Illinois State University

ISU ReD: Research and eData

Theses and Dissertations

6-29-2015

\title{
Longitudinal Effects of School Climate on Middle-School Students' Academic, Social-Emotional and Behavioral Outcomes
}

Jennifer Lynn Engelland-Schultz

Illinois State University, jespsych15@gmail.com

Follow this and additional works at: https://ir.library.illinoisstate.edu/etd

Part of the Developmental Psychology Commons, Educational Psychology Commons, Elementary and Middle and Secondary Education Administration Commons, and the Junior High, Intermediate, Middle School Education and Teaching Commons

\section{Recommended Citation}

Engelland-Schultz, Jennifer Lynn, "Longitudinal Effects of School Climate on Middle-School Students' Academic, Social-Emotional and Behavioral Outcomes" (2015). Theses and Dissertations. 442.

https://ir.library.illinoisstate.edu/etd/442

This Dissertation is brought to you for free and open access by ISU ReD: Research and eData. It has been accepted for inclusion in Theses and Dissertations by an authorized administrator of ISU ReD: Research and eData. For more information, please contact ISUReD@ilstu.edu. 


\title{
LONGITUDINAL EFFECTS OF SCHOOL CLIMATE ON MIDDLE-SCHOOL STUDENTS' ACADEMIC, SOCIAL-EMOTIONAL AND BEHAVIORAL OUTCOMES
}

\author{
Jennifer L. Engelland-Schultz
}

108 Pages

August 2015

Millions of youth are at risk for low academic achievement, school dropout, risky behavior, bullying, and mental health concerns, especially those living in rural areas. Protective factors can reduce the likelihood of children and adolescents experiencing these negative outcomes. Research shows that positive school climate is a powerful protective factor for youth. The present study investigated the longitudinal relations between middle school students' school climate perceptions and their academic, socialemotional, and behavioral development over two years. Specifically, 510 students in grades 5-9 from six rural schools rated their support and influence at school as well as their internalizing problems, personal adjustment, and risky behavior. Students' academic performance was progress monitored using reading and math curriculum-based measures. Data were examined using Hierarchical Linear Modeling (HLM). Results revealed significant relations between students' perceived school climate and their socialemotional, behavioral, and mathematics outcomes over time. Further, school climate was a predictor of students' future involvement in risky behavior. There was a slight negative trend in students' perceived school climate as well as increases in their social-emotional 
problems and risky behavior, which suggests the need to implement evidence-based school climate improvement strategies aligned to students' developmental levels.

Findings indicate the importance of incorporating school climate assessment and improvement strategies in school practices and policies to enhance student outcomes and school contexts. Limitations and future directions for research are discussed based on results from the present study and the school climate literature. Overall, school climate significantly influences outcomes for youth. 
LONGITUDINAL EFFECTS OF SCHOOL CLIMATE ON MIDDLE-SCHOOL STUDENTS' ACADEMIC, SOCIAL-EMOTIONAL AND BEHAVIORAL OUTCOMES

JENNIFER L. ENGELLAND-SCHULTZ

\author{
A Dissertation Submitted in Partial \\ Fulfillment of the Requirements \\ for the Degree of \\ DOCTOR OF PHILOSOPHY \\ Department of Psychology \\ ILLINOIS STATE UNIVERSITY
}

2015 
(C) 2015 Jennifer L. Engelland-Schultz 
LONGITUDINAL EFFECTS OF SCHOOL CLIMATE ON MIDDLE-SCHOOL STUDENTS' ACADEMIC, SOCIAL-EMOTIONAL AND BEHAVIORAL OUTCOMES

JENNIFER L. ENGELLAND-SCHULTZ

COMMITTEE MEMBERS:

Renée M. Tobin, Co-Chair

Adena B. Meyers, Co-Chair

W. Joel Schneider

April L. Mustian 


\section{ACKNOWLEDGMENTS}

Completing a dissertation requires effort and collaboration from many

individuals. I am thankful to have so many remarkable people at Illinois State University (ISU) and in my family who have provided me with tremendous guidance, support, and encouragement throughout the process. I am also grateful to all of the families who dedicated their time and effort to participate in the study. It was these hundreds of individuals who made this project possible.

I would particularly like to thank Dr. Renée M. Tobin for co-chairing my dissertation. She has provided me with direction and support throughout the entire process. Beyond my dissertation, she has been a great mentor. She has always been there to talk to me about academics as well as life. She has provided me with encouragement during challenging times when I thought I could not make it. I could not have become a school psychologist without her. Renée, thank you for everything.

I would like to also thank Dr. Adena B. Meyers for co-chairing my dissertation. I have appreciated all of her guidance and feedback at each point in the process. I have learned a lot from her during our many hours of supervision across settings. It was fun being on the research team with her for four years. I also appreciated her encouraging me to run my first half-marathon. Thank you for all of your support, Adena.

Additionally, I would like to thank Dr. W. Joel Schneider for serving on my dissertation committee. I have appreciated him being patient with me when he had to 
explain data analyses multiple times for me to understand it. He made learning about HLM enjoyable. I have also appreciated him teaching me efficient technological tips and interesting life facts.

I would like to thank Dr. April Mustian for being part of my dissertation committee. I really appreciated her responding to so many of my emails about scheduling. She has added a valuable educational perspective to this project.

Also, I would like to thank the Livingston County Children's Network (LCCN), especially Dr. Brenda J. Huber for writing and leading this grant and Dr. Kristal H. Shelvin for all of her scheduling efforts and responding to so many of my emails. Additionally, I would like to thank all of the graduate and undergraduate students who have worked on the LCCN Program Evaluation team. It was their many hours of bubbling forms, preparing packets, administering surveys, and entering data that led to the completion of this research project.

And of course, I would especially like to thank my amazing husband (Wayne Schultz), parents (Maribeth and Peter Engelland), siblings (Samantha, Bianca, Brittany, Tiffany, Peter, and Kaitlyn Engelland) and grandparents (Kay and Peter Engelland). They have provided me with so much love, support, and encouragement over the years. They have always told me that I could reach my dreams. I am truly grateful to have such remarkable people in my life. Thank you for everything.

J.L.E.S. 


\section{CONTENTS}

Page

ACKNOWLEDGMENTS $\quad$ i

CONTENTS

TABLES $\quad \mathrm{V}$

FIGURES $\quad$ vi

CHAPTER

I. THE PROBLEM AND ITS BACKGROUND 1

II. REVIEW OF RELATED LITERATURE 5

Theoretical Perspectives on Development 5

Historical Overview of School Climate $\quad 7$

Modern Conceptualization of School Climate 9

Assessment of School Climate 10

Legislation on School Climate $\quad 10$

Rural Communities and School Climate 13

$\begin{array}{ll}\text { Analysis of School Climate } & 14\end{array}$

Theoretical Models of School Climate $\quad 15$

$\begin{array}{ll}\text { Research on School Climate } & 18\end{array}$

School Climate: Social Dimension $\quad 18$

School Climate: Academic Dimension $\quad 22$

School Climate: Physical Dimension $\quad 24$

Conclusion of School Climate Research 26

Purpose of Present Study 27 
III. RESEARCH DESIGN 34

Study Overview $\quad 34$

Research Participants $\quad 36$

Predictor Variables $\quad 36$

Social Climate Perceptions 36

$\begin{array}{ll}\text { Outcome Variables } & 37\end{array}$

Internalizing Problems $\quad 38$

Personal Adjustment $\quad 39$

Risky Behavior $\quad 39$

Academic Achievement $\quad 40$

$\begin{array}{ll}\text { Procedure } & 40\end{array}$

IV. ANALYSIS OF THE DATA 42

Question 1: Do Grade Level and Gender Predict Students' Initial School Climate Perceptions? 42

Question 2: Do Middle School Students' School Climate Perceptions Change Over Time?

Question 3: Are Students' School Climate Perceptions Concurrently Related to Their Academic, Social-Emotional, and Behavioral Functioning?

Question 4: Are There Unidirectional Effects Between Students' School Climate Perceptions and Academic, Social-Emotional, and Behavioral Functioning?

Post-Hoc Analyses $\quad 62$

V. SUMMARY, CONCLUSIONS, AND RECOMMENDATIONS 74

$\begin{array}{ll}\text { REFERENCES } & 99\end{array}$ 


\section{TABLES}

Table $\quad$ Page

1. Data Collection: Archival and Measures 35

2. Hierarchical Linear Modeling of School Climate Over Time 46 


\section{FIGURES}

Figure

1. Question 1: Hypothesized Predictors (i.e., Grade and Gender) of School Climate

2. Question 2: Hypothesized Changes in School Climate Over Time

3. Question 3: Hypothesized Concurrent Relations Between School Climate and Students' Academic, Social-Emotional, and Behavioral Functioning at Each Assessment Time

4. Question 4: Hypothesized Unidirectional Relations with Students' Previous School Climate Perceptions Predicting Their Subsequent Academic, SocialEmotional, and Behavioral Functioning

5. Question 1: Hypothesized Predictors (i.e., Grade and Gender) of School Climate

6. Question 1: Results for Predictors (i.e., Grade and Gender) of School Climate

7. Question 2: Hypothesized Changes in School Climate Over Time

8. Question 2: Results for Changes in School Climate Over Time

9. Question 2: Results for Observed and Predicted Changes in School Climate Across Grades

10. Question 3: Hypothesized Concurrent Relations Between School Climate and Students' Academic, Social-Emotional, and Behavioral Functioning at Each Assessment Time

11. Question 3: Results for Concurrent Relations Between School Climate and Students' Academic Functioning

12. Question 3: Results for Concurrent Relations Between School Climate and Students' Behavioral Functioning 
13. Question 3: Results for Concurrent Relations Between School Climate and Students' Social-Emotional Functioning

14. Question 4: Hypothesized Unidirectional Relations with Students' Previous School Climate Perceptions Predicting Their Subsequent Academic, SocialEmotional, and Behavioral Functioning

15. Question 4: Results for Unidirectional Relations Between Students' Previous School Climate Perceptions and Their Future Math Computation Performance

16. Question 4: Results for Unidirectional Relations Between Students' Previous School Climate Perceptions and Their Future Math Problem Solving Performance

17. Question 4: Results for Unidirectional Relations Between Students' Previous School Climate Perceptions and Their Future Reading Comprehension Performance

18. Question 4: Results for Unidirectional Relations Between Students' Previous School Climate Perceptions and Their Future Reading Fluency Performance

19. Question 4: Results for Unidirectional Relations Between Students' Previous School Climate Perceptions and Their Future Fighting

20. Question 4: Results for Unidirectional Relations Between Students' Previous School Climate Perceptions and Their Future Cigarette Use

21. Question 4: Results for Unidirectional Relations Between Students' Previous School Climate Perceptions and Their Future Alcohol Use

22. Question 4: Results for Unidirectional Relations Between Students' Previous School Climate Perceptions and Their Future Carrying of Weapons 60

23. Question 4: Results for Unidirectional Relations Between Students' Previous School Climate Perceptions and Their Future Internalizing Problems

24. Question 4: Results for Unidirectional Relations Between Students' Previous School Climate Perceptions and Their Future Personal Adjustment 62

25. Post-Hoc: Results for Predicted Changes in Students' Internalizing Problems Across Grades 
26. Post-Hoc: Results for Predicted Changes in Students' Personal Adjustment Across Grades

27. Post-Hoc: Results for Predicted Changes in Students' Alcohol Use Across Grades

28. Post-Hoc: Results for Predicted Changes in Students' Cigarette Use Across Grades

29. Post-Hoc: Results for Predicted Changes in Students' Math Computation Performance Across Grades

30. Post-Hoc: Results for Predicted Changes in Students' Math Problem Solving Performance Across Grades

31. Post-Hoc: Results for Predicted Changes in Students' Reading Comprehension Performance Across Grades

32. Post-Hoc: Results for Predicted Changes in Students' Reading Fluency Performance Across Grades 


\section{CHAPTER I}

\section{THE PROBLEM AND ITS BACKGROUND}

Across the nation, millions of children and adolescents experience bullying, academic problems, pressure to engage in risky behaviors, and social-emotional/mental health concerns. These concerns are interrelated and associated with long-term negative outcomes. For instance, between 20 to 56 percent of youth are involved in bullying each year with middle school students being at the highest risk (Hertz \& Donato, 2013).

Seven percent of 16 to 24 year olds have dropped out of high school and not earned their diploma or GED (National Center for Education Statistics; NCES, 2012). On a national survey, about 25 percent of high school students reported having grades of mostly Cs or worse with this lower academic performance being linked to increased involvement in risky behavior (Center for Disease Control and Prevention; CDC, 2009). Up to 20 percent of children and adolescents experience at least one diagnosable mental disorder every year with these rates on the rise (CDC, 2013). About 4,600 youth lose their lives to suicide each year making it the third leading cause of death for 10 to 24 year olds (CDC, 2013).

Of particular concern are youth who experience these concerns and reside in rural areas. Children and adolescents in rural communities are at risk for not receiving appropriate services and supports due to a variety of barriers (e.g., underfunded schools, stigma, and inaccessible services) (Fagan \& Hughes, 1985; Helge, 1985; Hughes, 1985; 
Kramer \& Peters, 1985; Kosciw, Greytak, \& Diaz, 2009; Maine Rural Health Research Center, 2009; Rural Education, 2011). There continues to be a lack of research on addressing barriers to service delivery and access in rural areas (Clopton \& Knesting, 2006).

Taken together, our nation's alarming statistics show a strong need for research on risk and protective factors that influence outcomes for youth, especially those who live in rural locations. To examine these factors, a developmental-ecological perspective is valuable for understanding children's development as it unfolds within their environments (Bronfenbrenner \& Ceci, 1994). Longitudinal research is useful in studying the effects of risk and protective factors on development (Kazdin, Kraemer, Kessler, Kupfer, \& Offord, 1997). Based on the research, we must develop evidencebased prevention and intervention strategies aimed at enhancing the lives of youth. Improving school climate is one strategy for improving student outcomes.

Researchers have demonstrated the effects of school climate on students' development and learning (e.g., Brand, Felner, Shim, Seitsinger, \& Dumas, 2003; Gregory, Cornell, \& Fan, 2011; Hoge, Smit, \& Hanson, 1990; Hopson \& Lee, 2011; Kasen, Cohen, \& Brook, 1998; Kuperminc, Leadbeater, \& Blatt, 2001; LaRusso \& Selman, 2011; Shirley \& Cornell, 2012; Shochet, Dadds, Ham, \& Montague, 2006; Steward \& Suldo, 2011; Suldo, McMahan, Chappel, \& Loker, 2012; Way et al., 2007). Policymakers and school leaders have become increasingly aware of this research and have developed policies and initiatives for school climate improvement. For example, the U.S. Department of Education's Office of Safe and Healthy Students funded the 
National Center on Safe Supportive Learning Environments (NCSSLE) to improve the climate of schools (American Institutes for Research, 2015). They funded two major grant initiatives, the Safe Supportive Schools (S3) in 2010 and Project Prevent (P2) in 2014, to improve students' engagement and safety in schools as well as the school environment (American Institutes for Research, 2015). As researchers continue to investigate school climate, the aim is to translate findings into policies and strategies for enhancing student outcomes.

In summary, millions of children and adolescents experience bullying, academic problems, pressure to engage in risky behaviors, and social-emotional/mental health concerns. Youth in rural areas might be at a greater risk for these problems due to several factors (e.g., poverty, stigma, lack of services). To address these pervasive concerns, we must increase protective factors in schools, such as by creating positive climates and implementing evidence-based prevention and intervention programs, especially in rural communities. School leaders and policymakers are instrumental in these efforts. Continued research is needed to understand the influence of school climate on students' developmental trajectories, particularly in rural locations.

The present study aimed to address gaps in the literature by investigating the effects of middle school students' perceptions of school climate on their academic, social-emotional/mental health, and behavioral trajectories over time in rural communities. Specifically, over a two-year period, I examined students' perceptions of support as well as autonomy and influence at school as predictors of their math and reading performance, internalizing problems (e.g., anxiety and depression), personal 
adjustment (e.g., self-esteem and interpersonal relations), and risky behavior (e.g., alcohol and cigarette use). In addition, I studied the direction of effects between students' perceived school climate and functioning. Findings shed light on the protective nature of school climate for middle school students in rural communities. 


\section{CHAPTER II}

\section{REVIEW OF RELATED LITERATURE \\ Theoretical Perspectives on Development}

The middle school years are a transitional time in children's development characterized by many biological, psychological, and social-emotional changes (Santrock, 2008). From a developmental-ecological perspective, reciprocal interactions take place between individuals and their environments (Bronfenbrenner \& Ceci, 1994). Thus, children's developmental trajectories are influenced by individual characteristics and social-contextual factors (Cook, Williams, Guerra, Kim, \& Sadek, 2010; Kärnä, Voeten, Poskiparta, \& Salmivalli, 2010; Kazdin, Kraemer, Kessler, Kupfer, \& Offord, 1997).

Bronfenbrenner (1977) viewed development as resulting from interactions between individuals and different levels of the environment. Bronfenbrenner (1977) defined the ecology of human development as the "scientific study of the progressive mutual accommodation, throughout the life span, between growing human organisms and the changing immediate environments... as well as the larger social contexts" (p. 514). Bronfenbrenner (1977) described four contextual levels (i.e., microsystem, mesosystem, exosystem, and macrosystem) influencing developmental trajectories. In regards to the microsystem, Benard (1991) asserted, "A powerful predictor of the outcome for children and youth is the quality of the immediate care giving environment" (p. 6). Research has 
demonstrated that high quality environments characterized by care and support, high expectations, and opportunities for active participation are protective factors for youth (Benard, 1991). These high quality environments can occur in different contexts, such as the family, school, and community (Benard, 1991).

Risk and protective factors can be internal or external to the child, such as within their biological makeup, cognition, family and peer relations, and broader social environment (McMahon \& Frick, 2005). Risk factors refer to antecedent conditions that increase the likelihood of undesirable outcomes while protective factors increase the probability of positive outcomes (Kazdin et al., 1997; Masten, 2007). Based on riskfactor theory, individuals' developmental trajectories are probabilistic and depend on the presence, absence, and interactions of risk and protective factors (Kazdin et al., 1997). Risk and protective factors influence developmental outcomes, such as the continuity or discontinuity of disorders (Cicchetti \& Rogosch, 2002). Research on resilience has shown that identifying protective factors is crucial for informing prevention and early intervention efforts (Masten, 2007).

To investigate the influence of risk and protective factors on developmental trajectories, longitudinal research is required to establish causal relations (Kazdin et al., 1997). Longitudinal designs reveal complex relations between antecedents and outcomes such that one antecedent might lead to different outcomes for different individuals (i.e., multifinality) while multiple antecedents might be related to one outcome (i.e., equifinality) (Cicchetti \& Rogosch, 2002; Kazdin et al., 1997). Empirically investigating 
the effects of risk and protective factors on outcomes is critical for developing effective prevention and intervention strategies for youth.

From an educational perspective, schools must strive to enhance protective factors and minimize risk factors to promote positive student outcomes. Schools can foster resilience by aligning prevention and intervention efforts to students' developmental needs (Cicchetti \& Rogosch, 2002). Stage-environment fit theory suggests that the academic and social environment at schools must match students' developmental needs to promote school engagement (DeWit, Karioja, \& Rye, 2010). One evidence-based strategy for enhancing students' developmental outcomes is establishing and maintaining a positive school climate (Thapa, 2013). Masten (2007) described school climate research as a "hot spot" for fostering resilience among students (p. 925). A large body of evidence suggests that school climate is associated with students' academic, socialemotional/mental health, and behavioral outcomes (e.g., Benner \& Graham, 2011; Brand et al., 2003; Crosnoe et al., 2002; DeWit et al., 2010; Gendron et al., 2012; Gregory et al., 2011; Hoge, Smit, \& Hanson, 1990; Hopson \& Lee, 2011; Kasen et al., 1990, 1998; Koth et al., 2008; Kuperminc et al., 1997, 2001; LaRusso \& Selman, 2011; McGraw, Moore, Fuller, \& Bates, 2008; Samdal et al., 1998; Shirley \& Cornell, 2012; Shochet, Dadds, Ham, \& Montague, 2006; Steward \& Suldo, 2011; Suldo et al., 2012; Way et al., 2007).

\section{Historical Overview of School Climate}

At the turn of the $20^{\text {th }}$ century, Arthur C. Perry was credited as the first person to study the relation between school climate and learning (Cohen, McCabe, Michelli, \& Pickeral, 2009; Thapa, 2013). Perry's (1908) book, titled The Management of a City 
School, addressed school staff members' responsibility for creating effective schools. Perry (1908) analyzed the school at the systems level and described it in terms of business principles. Perry (1908) noted the importance of community outreach, interpersonal relations, and positive environmental factors. Additionally, Perry (1908) described students' social interactions, academic progress, behavior, moral development, physical welfare, and school spirit. Essentially, Perry (1908) recognized links between school climate and student outcomes.

Another important figure in school climate research was John Dewey, who was one of the most influential educators of the $20^{\text {th }}$ century (Sadker \& Zittleman, 2007). Dewey has been described as the grandfather of modern research in social, emotional, ethical, and academic education (Cohen, 2006). Dewey studied different aspects of school life and promoted progressive education, which encouraged schools to focus on family and community issues, apply social sciences research in the classroom, and use a democratic approach to meet the needs of diverse students (Cohen, McCabe, et al., 2009; Collins \& Parson, 2010; Sadker \& Zittleman, 2007). These objectives have continued to be endorsed by educators and policymakers and investigated by researchers. Cohen (2006) asserted that education should focus not only on academics but also on social, emotional, and ethical competencies, which "provide the foundation for participation in a democracy and improved quality of life" (p. 201). Dewey's work in education was foundational for research on school climate and student outcomes.

It was not until the 1950s that researchers began systematically studying school climate (Cohen, McCabe, et al., 2009). Halpin and Croft (1963) were the first to 
quantitatively measure school climate and relate it to school effectiveness (Anderson, 1982; Collins and Parson, 2010). An organizational perspective on school climate guided early research on school climate (Anderson, 1982). For instance, Tagiuri (1968) described climate in terms of the ecology (i.e., building features and school size), milieu (i.e., student and teacher characteristics), social system (i.e., relationships and instruction), and culture (i.e., beliefs, values, and norms) (as cited in Anderson, 1982). Tagiuri's (1968) classification system paved the way for future researchers to comprehensively examine school climate.

Despite differences in school climate conceptualization, Anderson (1982) reported several areas of agreement including the following: 1) schools have unique climates, 2) school climate is complex and difficult to measure, 3) school climate is influenced by student body characteristics and classroom dynamics, 4) school climate influences student outcomes, and 5) studying school climate will increase the understanding and prediction of student behavior. These points of agreement have guided recent school climate research.

\section{Modern Conceptualization of School Climate}

School climate is a broad term that encompasses many school experiences. School climate is defined as the "quality and character of school life...based on patterns of students', parents', and school personnel's experience of school life" (National School Climate Center, NSCC, 2015). Some researchers have a three-dimensional conceptualization of school climate that includes social, academic, and physical factors (Character Education Partnership, CEP, 2013; Loukas, 2007; National Association of 
Elementary School Principals, NAESP, 2013). Other researchers have a four-

dimensional view of school climate that consists of interpersonal relationships, safety, teaching and learning practices, and the institutional environment (NSCC, 2015).

Additionally, leadership and professional relationships are part of school climate, which should be assessed by school staff (NSCC, 2015). Overall, most researchers agree that school climate is a multidimensional construct shaped by social, academic, and physical factors (CEP, 2013; Cohen, McCabe, et al., 2009; Cohen, Pickeral, McCloskey, 2009; Collins \& Parsons, 2010; Loukas, 2007; NSCC, 2012; Hopson \& Lawson, 2011).

\section{Assessment of School Climate}

Assessments for measuring school climate have been available for many years. However, as a result of the research to practice gap, using these measures in schools has not been widespread. Currently, more schools have recognized the links between students' school climate perceptions and outcomes. Some schools have started using data from school climate assessments to guide their educational practices (Cohen, 2006). Cohen (2006) asserted, "Positive school climate and social-emotional competencies are associated with and predictive of success; educators have a responsibility to monitor them" (p. 218). Overall, research has consistently demonstrated the significant influence of school climate on student outcomes. School climate assessments have been gradually incorporated into school improvement plans.

\section{Legislation on School Climate}

Over the past decade, empirical findings have informed school leaders and policymakers about the importance of school climate assessment and improvement. 
Cohen (2006) stated, "Socially, emotionally, and physically safer schools has become a primary focus of the U.S. Department of Justice and virtually all state education departments," which was evidenced by the U.S. Department of Education's Office of Safe and Drug-Free Schools in 2004 (p. 213).

The National School Climate Council (NSCC, 2009) developed The National School Climate Standards to provide policymakers and school leaders with effective practices for improving school climate. These five standards include: 1) creating a shared vision and plan for positive school climate, 2) having policies that promote students' learning and development and address barriers to teaching and learning, 3) identifying and prioritizing school policies and practices, 4) establishing a welcoming, supportive, and safe school environment, and 5) developing practices that "promote social and civic responsibilities and a commitment to social justice" (NSCC, 2009, p. 3). Each of these standards was further divided into indicators and sub-indicators to assist with implementation. Ideally, policymakers and school leaders will use these standards to improve school climate across the nation.

In 2011, the National School Climate Center (NSCC) examined school climate policies across the United States (Piscatelli \& Lee, 2011). Despite an abundance of research showing the importance of school climate, only 24 states had policies addressing school climate, and only 12 states had comprehensive definitions of school climate (Cohen, McCabe, et al. 2009; Piscatelli \& Lee, 2011). Further, there were limited guidelines for assessing school climate within these policies (Piscatelli \& Lee, 2011). Cohen, McCabe, et al. (2009) found that only 22 states included school climate policy as 
part of their improvement and accreditation systems. Nonetheless, Cohen, Pickeral, et al. (2009) reported that more schools have started collecting and using school climate data to measure school success more broadly. Taken together, more policymakers and school leaders have implemented school climate policies; however, the research-to-practice gap in the area of school climate improvement continues to exist.

The U.S. Department of Education's Office of Safe and Healthy Students has recognized the importance of school climate on students' learning and development. They funded the National Center on Safe Supportive Learning Environments (NCSSLE) to improve the climate of schools (American Institutes for Research, 2015). The NCSSLE identified the following objectives: 1) improve student engagement by enhancing cultural and linguistic competence, relationships, and school participation, 2) increase students' emotional and physical safety while decreasing bullying and substance abuse, and 3) improve students' physical and mental health, schools' physical and instructional environment, and discipline practices (American Institutes for Research, 2015). To accomplish these goals, the NCSSLE provided $\$ 38.8$ million in Safe Supportive Schools (S3) grants to 11 states in 2010 and \$14.2 million in Project Prevent (P2) grants to 22 local educational agencies in 2014 (American Institutes for Research, 2015).

Overall, more policymakers and school leaders are recognizing the importance of assessing and improving school climate to enhance students' learning and development. Nevertheless, more research is needed to clarify relations between school climate and 
student outcomes to promote further school climate legislation. In particular, there is a strong need for research on school climate in rural areas.

\section{Rural Communities and School Climate}

Youth across the nation experience bullying, academic problems, pressure to engage in risky behavior, and mental health concerns. However, youth in rural areas are at an increased risk for not receiving proper interventions and treatment due to barriers in accessing services and supports (Maine Rural Health Research Center, 2009). There is demand for research on the needs of youth and families and service delivery models in rural locations.

In the 1980s, researchers studied service delivery in rural areas and identified several barriers (e.g., dispersed populations, long-distance transportation, poverty, low salaries, professional isolation and turnover, adherence to traditional practices, stigma, and a lack of mental health services) (Fagan \& Hughes, 1985; Helge, 1985; Hughes, 1985; Kramer \& Peters, 1985). Many of these same barriers continue to persist in rural locations (Clopton \& Knesting, 2006). The National Education Association (NEA; 2013) reported that rural schools receive only 22 percent of the federal education funding but educate 40 percent of the nation's students. About 41 percent of students in rural areas were in poverty (Strange, Johnson, Showalter, \& Klein, 2012). Further, youth in rural locations were 20 percent less likely to have mental health visits than youth in urban areas even after controlling for insurance status (Maine Rural Health Research Center, 2009). Taken together, poverty, stigma, and other barriers to accessing services are risk factors for youth and families in rural areas. 
Nonetheless, rural communities are heterogeneous with unique needs and strengths (Fagan \& Hughes, 1985). It is important for researchers to conduct assessments to identify community strengths and needs as well as to develop service delivery models aimed at decreasing risk factors and increasing protective factors. Clopton and Knesting (2006) stated that a major strength for rural schools is the positive relationships between students, teachers, and families. More research is needed on the effects of school climate and school-based services on student outcomes in rural communities.

\section{Analysis of School Climate}

The effects of school climate on student outcomes have been studied using different approaches. Researchers have examined both the subjective and objective nature of school climate. However, most researchers have conceptualized school climate as individuals' perceived experiences and have assessed school climate using subjective measures (Cohen, 2006; Cohen, McCabe, et al., 2009). Results have shown stronger relations between school climate and student outcomes when using subjective measures as opposed to objective indicators (e.g., resources, teacher qualifications, or school building features) (Kuperminc, Leadbeater, Emmons, \& Blatt, 1997). However, Kuperminc, Leadbeater, and Blatt (2001) stated that changes in the objective school climate might influence subjective perceptions. Similarly, Way, Reddy, and Rhodes (2007) stated that future research should examine both the subjective and objective aspects of school climate to determine potential discrepancies.

Students' school climate perceptions are also influenced by their individual characteristics, which result in within-school variability in perceived climate (Loukas, 
2007). Researchers have found that both individual-level and school-level climate influence student outcomes (e.g., Brand, Felner, Shim, Seitsinger, \& Dumas, 2003; Koth et al., 2008; Suldo, McMahan, Chappel, \& Loker, 2012). Examining climate at the individual and school levels can assist with identifying students who are at risk for adverse outcomes and with recognizing areas for school climate improvement. Thus, it is beneficial to examine school climate at multiple contextual levels.

\section{Theoretical Models of School Climate}

"School climate theory suggests that the school's social system, culture, milieu, and ecological structure affect student outcomes" (Zaykowski \& Gunter, 2011, p. 431). Many cross-sectional studies have revealed associations between school climate and student outcomes (e.g., Brand et al., 2003; Gregory et al., 2011; Hoge, Smit, \& Hanson, 1990; Hopson \& Lee, 2011; Koth et al., 2008; Kuperminc et al., 1997; LaRusso \& Selman, 2011; Samdal et al., 1998; Shirley \& Cornell, 2012; Steward \& Suldo, 2011; Suldo et al., 2012). Further, several longitudinal studies have explored climate as a predictor of student outcomes (e.g., Benner \& Graham, 2011; Crosnoe et al., 2002; DeWit et al., 2010; Gendron et al., 2012; Kasen et al., 1990, 1998; Kuperminc et al., 2001; McGraw et al., 2008; Shochet et al., 2006; Way et al., 2007). However, only a few researchers, such as Kuperminc et al. (2001), Shochet et al. (2006), and Way et al. (2007), have examined the direction of effects between climate and students' functioning.

Way et al. (2007) conducted a three-year longitudinal study to examine sixth through eighth grade students' school climate perceptions (i.e., clarity and consistency of rules, teacher support, peer support, and student autonomy) on their self-reported 
depression, self-esteem, and problem behavior in 22 schools. Findings indicated that school climate perceptions were significantly associated with depression, self-esteem, and behavior problems. Gender differences showed that girls initially had more positive school climate perceptions than boys but experienced steeper declines in perceived peer support over time. In general, students' school climate perceptions became more negative over time. However, for students whose school climate perceptions became more positive, they experienced decreases in depressive symptoms and behavior problems as well as increases in self-esteem. Way et al. (2007) found that students' initial levels of self-esteem and depression did not predict most aspects of their perceived school climate. However, students' initial levels of behavior problems predicted their school climate perceptions. Overall, there were unidirectional relations with school climate perceptions predicting self-esteem and depression but bidirectional relations between climate perceptions and behavior problems.

In a one-year longitudinal study, Shochet et al. (2006) explored the effects of eighth grade students' perceived social climate (i.e., sense of belonging, respect, encouragement, acceptance, and inclusion) on their self-reported depression, anxiety, and general functioning (i.e., hyperactivity, emotional symptoms, conduct problems, and peer problems) in 14 Australian schools. Results demonstrated that students' perception of school connectedness was moderately stable and associated with all outcomes with gender moderating these relations such that school connectedness predicted depression for boys and girls, anxiety for girls only, and general functioning for boys only. There 
were unidirectional relations only with school connectedness predicting functioning but not the reverse.

Kuperminc et al. (2001) used a one-year longitudinal design to explore the effects of sixth and seventh grade students' perceived school climate (i.e., achievement motivation, fairness, order and discipline, parent involvement, sharing of resources, interpersonal relations, and student-teacher relationships) as a moderator of self-criticism and self-efficacy on internalizing and externalizing problems at a large middle school in a metropolitan area. Findings revealed that students' climate perceptions became more negative throughout the year for both males and females. However, climate perceptions served as a protective factor against increases in internalizing and externalizing problems for students who were self-critical and had low self-efficacy. Students' initial levels of internalizing and externalizing problems did not predict their later climate perceptions.

Overall, these longitudinal studies provide support for examining students' perceived school climate as a predictor of their functioning. It is important that researchers found primarily unidirectional effects with climate perceptions predicting functioning. These findings showed that students' future climate perceptions were not biased by their initial functioning but did have the potential to improve their functioning. A developmental-ecological approach should be used to create school environments that align with students' developmental needs over time. More longitudinal studies are needed to further investigate the effects of school climate on students' development and learning during middle school to improve student outcomes and school contexts. 


\section{Research on School Climate}

Over the past two decades, there has been an increased interest among researchers, policymakers, and school leaders in the effect of school climate on students' performance. School climate dimensions include social, academic, and physical factors (CEP, 2013; Loukas, 2007; NSCC, 2012; Hopson \& Lawson, 2011; Cohen, McCabe, et al., 2009; Cohen, Pickeral, et al. 2009; Collins \& Parsons, 2010). Findings have consistently demonstrated significant relations between school climate and students' academic, social-emotional/mental health, and behavioral outcomes.

\section{School Climate: Social Dimension}

The social dimension of school climate pertains to the "quality of interpersonal relationships between and among students, teachers, and staff; equitable and fair treatment of students by teachers and staff; degree of competition and social comparison between students; and degree to which students, teachers, and staff contribute to decisionmaking at the school" (CEP, 2013; Loukas, 2007, p. 1). Similarly, other definitions of the social climate include being respectful of diversity and having supportive adults and peers (NSCC, 2012). Across studies, research has indicated that the social climate of schools is related to students' behavioral, social-emotional, and academic outcomes.

In terms of behavioral outcomes, Shirley and Cornell (2012) found that middle school students who experienced a positive social climate (i.e., teacher support and less acceptance of aggression among peers) had fewer behavior problems (i.e., office discipline referrals and suspensions). Kasen et al. (1990) found that when students attended schools with a negative social climate (i.e., high conflict), they displayed more 
behavior problems (e.g., alcohol use, conduct problems, oppositional behavior).

Additionally, when schools had high conflict and encouraged social interactions, students had increases in behavior problems; however, when schools had low conflict and encouraged social interactions, students had decreases in behavior problems (Kasen et al., 1990). Having a negative social climate in schools has also been linked to students experiencing more victimization (O’Brennan \& Furlong, 2010; Zaykowski \& Gunter, 2011). Students' behavioral trajectories are influenced by school climate and peer relations, which have the potential to be risk or protective factors for them. These studies demonstrated the relations between the social climate of schools and students' behavioral outcomes.

In addition to behavioral functioning, researchers have examined relations between the social climate of schools and students' social-emotional outcomes. As mentioned, in a three-year longitudinal study, Way et al. (2007) found that declines in the perceived social climate (i.e., support and student autonomy) led to increases in middle school students' depression and behavior problems and decreases in their self-esteem. In another longitudinal study described earlier, Shochet et al. (2006) found that gender moderated predictive relations between perceived social climate (i.e., sense of belonging, respect, encouragement, and acceptance and inclusion) and middle school students' internalizing problems and behavior. Specifically, positive social climate perceptions predicted fewer depressive symptoms for boys and girls, fewer anxiety symptoms for girls, and better behavioral functioning for boys (Shochet et al., 2006). Similarly, in a one-year longitudinal study, McGraw, Moore, Fuller, and Bates (2008) examined the 
effects of high school students' perceived social climate (i.e., school, peer, and family connectedness) on their anxiety, stress, depression, and overall negative affect in Australian schools (McGraw et al., 2008). Findings revealed that more negative social climate perceptions were associated with higher levels of anxiety, stress, depression, and overall negative affect (McGraw et al., 2008). Further, Suldo et al. (2012) found that high school students' positive perceptions of social support (i.e., peer relations, studentteacher relations, parent involvement) were related to fewer internalizing and externalizing problems as well as higher life satisfaction. LaRusso, Romer, and Selman (2008) also found that high school students' perceived social climate (i.e., support, respect, and belonging) was related to their depressive symptoms and risky behaviors (e.g., drug use). These studies show that the social climate of schools can have a positive or negative influence on students' social-emotional and behavioral functioning.

Researchers have also examined relations between the social dimension of school climate and students' academic outcomes. In a two-year longitudinal study, Hoge et al. (1990) found that middle school students' perceptions of the social climate (i.e., teacher interactions and practices) were associated with increases in academic self-esteem. In another two-year study, Nasir, Jones, and McLaughin (2011) examined the relation between high school students' perceived social climate (i.e., connectedness) and academic achievement. Results indicated that positive social climate perceptions were related to higher academic achievement (Nasir et al., 2011). Similarly, Wilkinson-Lee, Zhang, Nuno, and Wilhelm (2009) found that middle school and high school students with positive perceptions of the social climate (i.e., school connectedness) had higher 
academic achievement and less emotional distress than those with more negative perceptions. Further, positive social climate was a protective factor for students by moderating relations between family obligations and emotional distress such that students with low to moderate family obligations had low emotional distress when they perceived a positive social climate (Wilkinson-Lee et al., 2009). In a one-year longitudinal study, DeWit et al. (2010) explored the effects of high school students' perceived social climate (i.e., teacher and peer support) on attendance in 23 schools in Canada. Students who perceived more negative social climates had decreases in school attendance over time (DeWit et al., 2010). Research has shown that school attendance has moderate to strong relations with academic achievement (Roby, 2003). These results showed that having a positive social climate at school and feeling a sense of connectedness has the potential to improve students' academic outcomes.

Some researchers have conducted comprehensive studies that examine relations between perceived social climate and students' functioning across domains. Specifically, Stewart and Suldo (2011) explored relations between middle school students' perceived social support (i.e., teacher, students, and parents) and their academic achievement, internalizing and externalizing problems, and life satisfaction. More social support was linked to fewer internalizing and externalizing problems as well as higher life satisfaction and academic achievement (i.e., GPA and standardized test scores) (Stewart \& Suldo, 2011). Similarly, Brand et al. (2003) examined relations between middle school students' perceived social climate (i.e., teacher support, peer interactions, student autonomy, and support for cultural pluralism) and their academic achievement, social- 
emotional adjustment, and behavior in over 240 schools. Perceived teacher support and positive peer interactions were associated with higher academic achievement and selfesteem as well as lower levels of depression, delinquency, and aggression (Brand et al., 2003). Perceived student autonomy was related to higher academic achievement (Brand et al., 2003). Support for cultural pluralism was associated with better academic, behavioral, and social-emotional functioning, especially for students of minority backgrounds (Brand et al., 2003).

Overall, research has demonstrated that the social climate of schools significantly influences students' development and learning. Specifically, students' perceived social climate is related to their behavioral outcomes (e.g., office discipline referrals and suspensions, risky behaviors, conduct problems, and victimization), social-emotional functioning (e.g., depression, anxiety, self-esteem, and life satisfaction), and academic performance (e.g., academic achievement, academic self-esteem, and attendance) (DeWit et al., 2012; Hoge et al., 1990; Kasen et al., 1990; Kasen et al., 1998; LaRusso et al., 2008; McGraw et al., 2008; Nasir et al., 2011; O’Brennan \& Furlong, 2010; Shirley \& Cornell, 2012; Shochet et al., 2006; Stewart \& Suldo, 2011; Suldo et al., 2012; Way et al., 2007; Wilkinson-Lee et al., 2009; Zaykowski \& Gunter, 201). Nonetheless, more studies are needed to examine the direction of relations between students' social climate perceptions and their development over time.

\section{School Climate: Academic Dimension}

The academic dimension of school climate refers to the support for academic and social-civic learning, quality of instruction, teacher expectations, and progress monitoring 
of student achievement (CEP, 2013; Loukas, 2007; NSCC, 2012). Studies have shown that the academic climate of schools has the potential to improve students' academic performance as well as their social-emotional and behavioral outcomes. For instance, Brand et al. (2003) examined the influence of the academic climate on middle school students' academic, social-emotional, and behavioral adjustment. Specifically, instructional innovation and relevance was associated with better academic adjustment and self-esteem as well as lower levels of depression and substance use (Brand et al., 2003).

In terms of behavioral outcomes, Kasen et al. (1990) found a link between middle school and high school students' perceived academic climate (i.e., the focus on academics) and their risky behavior. Results showed that having a stronger academic climate predicted lower levels of alcohol use, conduct problems, and oppositional behavior for students (Kasen et al., 1990). Similarly, in a later study, Kasen et al. (1998) found that having a learning-focused climate predicted less deviant behavior in the future (Kasen et al., 1998). In another longitudinal study, Crosnoe, Erickson, and Dornbusch (2002) found that having a positive orientation to school (i.e., commitment to learning and school engagement) was associated with high school students having higher academic achievement and fewer delinquent behaviors.

In sum, researchers have demonstrated links between schools' academic climates and student outcomes beyond their academic performance. Specifically, researchers have found relations between schools' academic climate and students' internalizing problems, 
self-esteem, risky behavior, and academic achievement (Brand et al., 2003; Crosnoe et al., 2002; Kasen et al., 1990, 1998).

\section{School Climate: Physical Dimension}

For the physical dimension of school climate, researchers have presented different definitions. Some researchers have examined safety and the school environment as two separate domains (e.g., NSCC, 2013). Others have combined these factors so that the physical dimension includes the "appearance of the school building and its classrooms; school size and ratio of students to teachers in the classroom; order and organization of classrooms in the school; availability of resources, and safety and comfort" (CEP, 2013; Loukas, 2007, p. 1). Nonetheless researchers have demonstrated the importance of creating safe, positive school environments to improve students' development.

For behavioral outcomes, Cohen and Thomas (1984) examined school conflict in relation to students' behavioral problems (i.e., detentions, suspensions, and expulsions) in 52 secondary schools in Australia (Cohen \& Thomas, 1984). Cohen and Thomas (1984) found that schools with high conflict had students with more detentions, suspensions, and expulsions than schools with low conflict. Similarly, in a seven-year longitudinal study, Kasen et al. (1998) found that associating with deviant peers mediated the relation between school-level conflict and behavior problems. Specifically, in high conflict schools, having deviant friends increased future behavior problems (e.g., committing crimes, alcohol abuse) while avoiding these types of peer relationships decreased future behavior problems (Kasen et al., 1990). Kasen et al. (1998) explained these results by stating that students who were exposed to school conflict and avoided deviant peers 
might have become more resilient to conforming to a deviant lifestyle as adults. Gottfredson et al. (2005) also found that high school students' perceived school discipline (i.e., fairness and clarity of rules) was associated with less delinquency and victimization. Further, perceived school discipline accounted for more variance in outcomes than demographic variables (e.g., race and ethnicity, student enrollment, gender, poverty) (Gottfredson et al., 2005). These studies show the potential for the physical climate of schools to positively or negatively influence students' behavioral functioning.

Researchers have also examined the relation between the physical dimension of school climate and students' social-emotional functioning. Way et al. (2007) explored middle school students' perception of school discipline as a predictor of their depressive symptoms, self-esteem, and behavior problems over time. Results revealed that students who became more positive in their perceptions of school discipline experienced a decrease in depression and behavior problems (Way et al., 2007). Additionally, Suldo et al., (2012) found that high school students' perceptions of the physical dimension (i.e., order and discipline, building appearance, resources) was associated with their internalizing problems above and beyond the influence of other school climate dimensions with more positive perceptions being linked to fewer internalizing problems (Suldo et al., 2012).

In a comprehensive study, Brand et al. (2003) explored the effects of students' perceptions of the physical climate (i.e., safety, discipline harshness, and clarity of rules and expectations) on their academic, social-emotional and behavioral outcomes. Brand et al. (2003) found that having a positive physical climate (i.e., clear rules and expectations 
and fewer safety problems) was related to students experiencing better academic adjustment and self-esteem as well as lower levels of depression, risky behavior, and aggression. Additionally, less disciplinary harshness was linked to better academic functioning and less delinquency and aggression (Brand et al., 2003).

In sum, researchers have demonstrated associations between students' perception of the physical climate of schools (i.e., safety, discipline, building appearance, and resources) and their academic achievement, internalizing problems, self-esteem, risky behavior, behavior problems, disciplinary referrals, and delinquency and aggression (Brand et al., 2003; Cohen \& Thomas, 1984; Gottfredson et al., 2005; Kasen, 1998; LaRusso \& Selman, 2011; Suldo et al., 2012; Way et al., 2007). This research shows the importance of creating a safe, well-structured school environment for students.

\section{Conclusion of School Climate Research}

Overall, researchers have consistently demonstrated links between school climate and student outcomes. The social, academic, and physical dimensions of school climate influence students' academic, social-emotional, and behavioral outcomes. However, more research is needed to better understand the relation between specific school climate dimensions and student functioning over time. Ideally, research findings will guide school climate improvement to enhance students' wellbeing and the functioning of schools.

\section{Purpose of Present Study}

Cross-sectional studies have demonstrated links between school climate and students' academic, social-emotional, and behavioral functioning. However, more 
longitudinal studies are needed to examine the protective role of school climate on students' outcomes by examining the direction of these relations over time. Additionally, more studies that include fifth grade students are needed to better understand the developmental trajectories of middle school students. Lastly, there has been a lack of studies investigating the effects of school climate on students' development in rural areas. Longitudinally examining relations between school climate and student outcomes will assist with the advancement of theoretical models on school climate and the development of strategies to improve the functioning of students and schools.

The purpose of the present study was to replicate previous studies and extend the literature on the effects of school climate on students' development and learning. This study used a longitudinal design to examine the effects of school climate on middle school students' academic, social-emotional, and behavioral functioning over two years in rural areas. Perceptions of the social climate included students' perceived support as well as their autonomy and influence at school. Students' functioning consisted of their academic performance, internalizing problems, personal adjustment, and risky behavior. My study was unique in that I included four cohorts of students in fifth grade over time and followed one of these cohorts until ninth grade. Further, I examined grade level and gender as predictors of students' initial climate perceptions. I also focused on school climate in rural areas to identify protective factors for youth residing in those areas. Lastly, I aimed to replicate findings on the direction of effects between perceived social climate and students' internalizing problems and extend the literature by examining 
additional outcomes (e.g., academic performance, personal adjustment, and risky behavior). The research questions and hypotheses guiding this study were the following:

1) Do grade level and gender predict students' initial school climate perceptions (see Figure 1)?

a. Students in higher grades (i.e., seventh and eighth) will have more negative initial school climate perceptions than students in lower grades (i.e., fifth and sixth) (Kuperminc et al., 2001; Way et al., 2007).

b. Girls will have more positive initial climate perceptions than boys (Way et al., 2007).

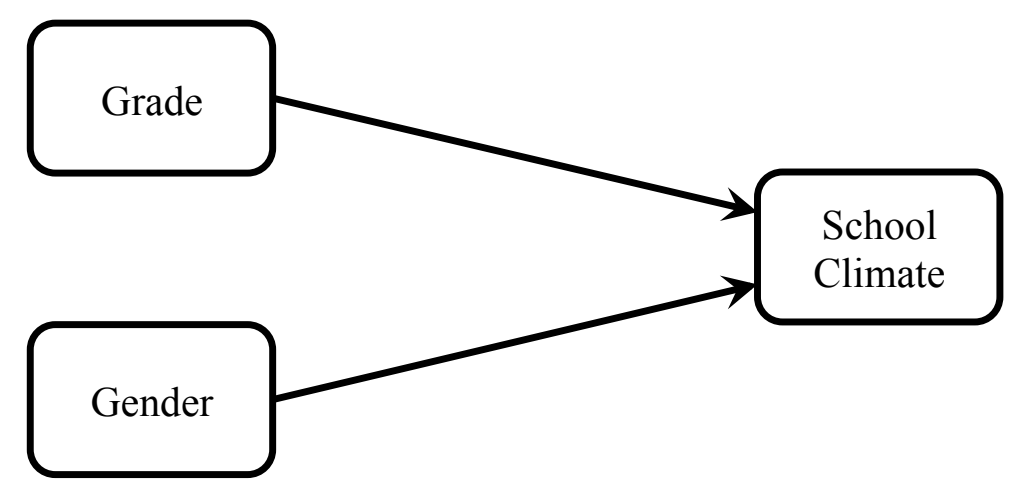

Figure 1. Question 1: Hypothesized predictors (i.e., grade and gender) of school climate. 
2) Do middle school students' school climate perceptions change based on their grade level (Figure 2)?

a. Students' school climate perceptions will become more negative as they enter higher grades (Kuperminc et al., 2001; Way et al., 2007).
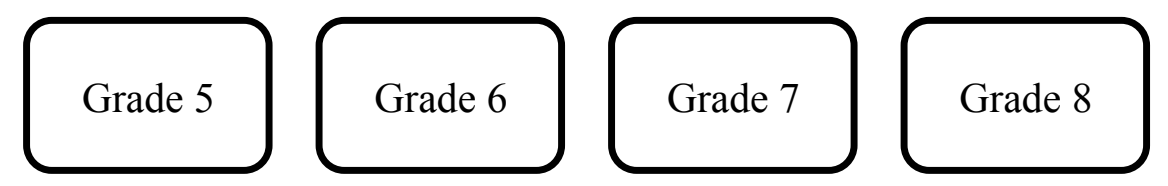

Grade 9

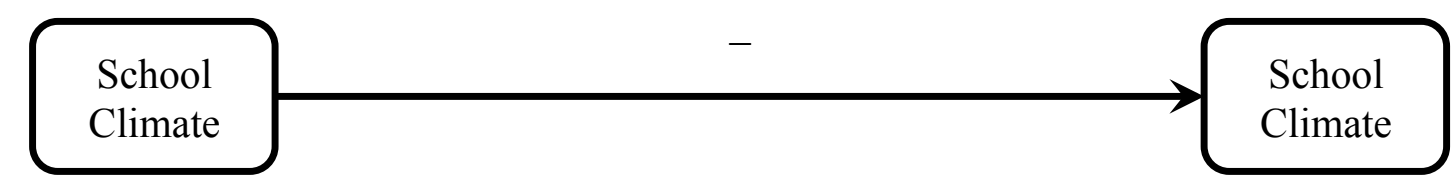

Figure 2. Question 2: Hypothesized changes in school climate over time. 
3) Are students' school climate perceptions concurrently related to their academic, behavioral, and social-emotional functioning (see Figure 3)?

a. Students' perceived school climate will be concurrently related to their academic achievement such that students with more positive climate perceptions will have higher academic test scores in reading and math than students with more negative perceptions (Brand et al., 2003; DeWit et al., 2010; Stewart \& Suldo, 2011).

b. Students' perceived school climate will be concurrently related to their selfreported risky behavior such that students with more positive climate perceptions will engage in less risky behavior than students with more negative perceptions (Brand et al., 2003; Kasen et al., 1990; LaRusso et al., 2008; LaRusso \& Selman, 2011; Zaykowski \& Gunter, 2011).

c. Students' perceived school climate will be concurrently related to their socialemotional functioning such that students with more positive climate perceptions will have fewer internalizing problems and better personal adjustment than students with more negative perceptions (Brand et al., 2003; LaRusso et al., 2008; Shirley \& Cornell, 2012; Stewart \& Suldo, 2011; Suldo et al., 2012; Way et al., 2007). 


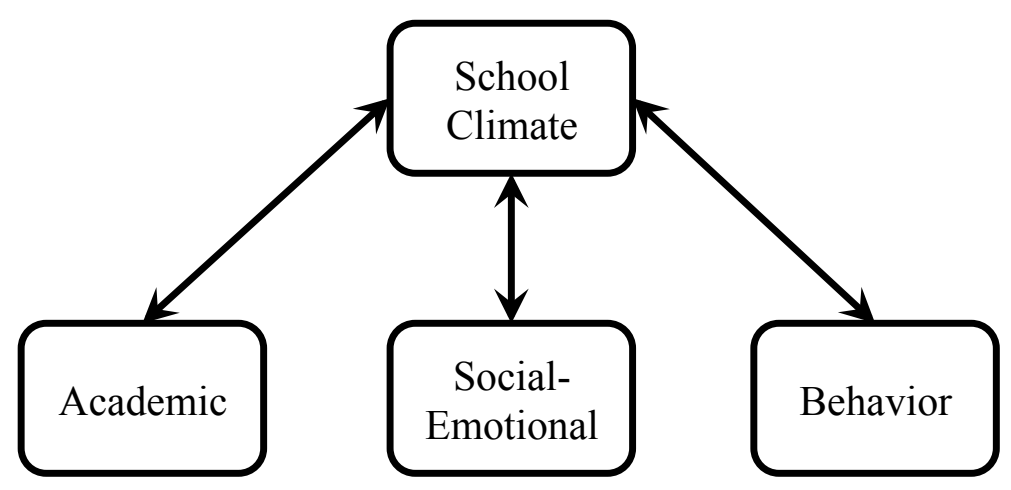

Figure 3. Question 3: Hypothesized concurrent relations between school climate and students' academic, social-emotional, and behavioral functioning at each assessment time. 
4) Are there unidirectional effects between students' school climate perceptions and academic, behavioral, and social-emotional functioning (see Figure 4)?

a. Relations between students' school climate perceptions and functioning will be unidirectional such that initial school climate perceptions will predict later academic functioning but initial academic functioning will not predict later school climate perceptions.

b. Relations between students' school climate perceptions and functioning will be primarily unidirectional such that initial school climate perceptions will predict later engagement in risky behavior but initial engagement in risky behavior will not predict later school climate perceptions (Kuperminc et al., 2001; Shochet et al., 2006).

c. Relations between students' school climate perceptions and functioning will be primarily unidirectional such that initial school climate perceptions will predict later internalizing problems and personal adjustment but initial internalizing problems and personal adjustment will not predict later school climate perceptions (Kuperminc et al., 2001; Shochet et al., 2006; Way et al., 2007). 


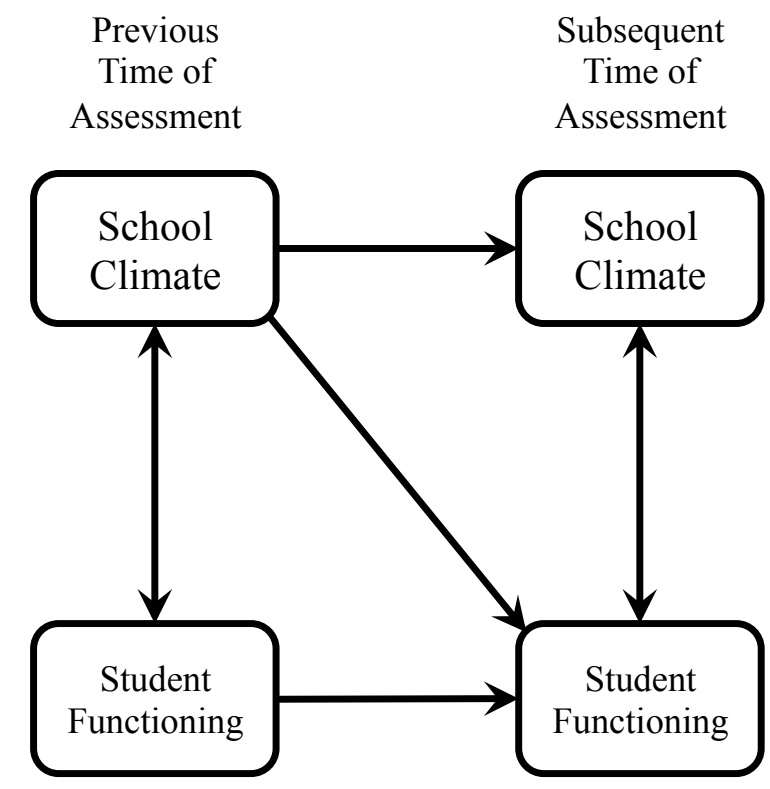

Figure 4. Question 4: Hypothesized unidirectional relations with students' previous school climate perceptions predicting their subsequent academic, social-emotional, and behavioral functioning. 


\section{CHAPTER III \\ RESEARCH DESIGN \\ Study Overview}

The primary purpose of the present study was to investigate the influence of school climate in rural middle schools on student outcomes over time. Specifically, I examined changes in fifth through ninth grade students' social climate perceptions in relation to their social-emotional, academic, and behavioral trajectories over two years. I investigated grade level and gender as predictors of students' initial perceptions of the social climate. Additionally, I examined the directional relation between the social climate and student outcomes over time.

This longitudinal study began in January of the 2011-2012 academic year at four middle schools in a rural county in the Midwest. Researchers obtained approval from the Institutional Review Board (IRB) at Illinois State University (ISU) prior to conducting the study. Data collection with middle school students continued the following two years in the four original schools and in two additional schools. Additionally, researchers collected data from ninth grade students who participated in the study during eighth grade. To examine relations between the perceived social climate and students' developmental trajectories over time, I used students' archival data and self-report data (see Table 1). Predictor variables included students' grade level, gender, and social climate perceptions. Outcome variables consisted of students' academic performance 
(i.e., AIMSweb scores in reading and math), social-emotional functioning (i.e., self-

reported internalizing problems and personal adjustment), and risky behaviors (i.e., self-

reported alcohol use, cigarette use, fighting, and carrying of weapons).

Table 1

Data Collection: Archival and Measures

\begin{tabular}{|c|c|c|c|c|c|}
\hline & Spring 2012 & Fall 2012 & Spring 2013 & Fall 2013 & Spring 2014 \\
\hline $5^{\text {th }}$ Grade & $\begin{array}{l}\text { COHORT A } \\
\text { 1. }{ }^{\mathrm{a}} \mathrm{SC} 5-6 \\
\text { 2. }{ }^{\mathrm{c}} \mathrm{BASC}-2 \\
\mathrm{n}=76\end{array}$ & $\begin{array}{l}\text { COHORT E } \\
\text { 1. SC 5-6 } \\
\text { 2. BASC-2 } \\
\mathrm{n}=76\end{array}$ & $\begin{array}{l}\text { COHORT E } \\
\text { 1. SC 5-6 } \\
\text { 2. BASC-2 } \\
\mathrm{n}=61\end{array}$ & $\begin{array}{l}\text { COHORT F } \\
\text { 1. SC 5-6 } \\
\text { 2. BASC-2 } \\
\mathrm{n}=7\end{array}$ & $\begin{array}{l}\text { COHORT F } \\
\text { 1. SC 5-6 } \\
\text { 2. BASC-2 } \\
\mathrm{n}=22\end{array}$ \\
\hline $6^{\text {th }}$ Grade & $\begin{array}{l}\text { COHORT B } \\
\text { 1. SC 5-6 } \\
\text { 2. BASC-2 } \\
\mathrm{n}=87\end{array}$ & $\begin{array}{l}\text { COHORT A } \\
\text { 1. SC 5-6 } \\
\text { 2. BASC-2 } \\
\mathrm{n}=77 \\
\end{array}$ & $\begin{array}{l}\text { COHORT A } \\
\text { 1. SC 5-6 } \\
\text { 2. BASC-2 } \\
\mathrm{n}=50 \\
\end{array}$ & $\begin{array}{l}\text { COHORT E } \\
\text { 1. SC 5-6 } \\
\text { 2. BASC-2 } \\
\mathrm{n}=10\end{array}$ & $\begin{array}{l}\text { COHORT E } \\
\text { 1. SC 5-6 } \\
\text { 2. BASC-2 } \\
\mathrm{n}=39\end{array}$ \\
\hline $7^{\text {th }}$ Grade & $\begin{array}{l}\text { COHORT C } \\
\text { 1. }{ }^{\mathrm{b} C} \text { SC } 8 \\
\text { 2. BASC-2 } \\
\text { 3. }{ }^{\mathrm{d}} \text { YRBS } \\
\mathrm{n}=48\end{array}$ & $\begin{array}{l}\text { COHORT B } \\
\text { 1. SC 7-8 } \\
\text { 2. BASC-2 } \\
\text { 3. YRBS } \\
\mathrm{n}=95\end{array}$ & $\begin{array}{l}\text { COHORT B } \\
\text { 1. SC 7-8 } \\
\text { 2. BASC-2 } \\
\text { 3. YRBS } \\
\mathrm{n}=80\end{array}$ & $\begin{array}{l}\text { COHORT A } \\
\text { 1. SC 7-8 } \\
\text { 2. BASC-2 } \\
\text { 3. YRBS } \\
\mathrm{n}=20\end{array}$ & $\begin{array}{l}\text { COHORT A } \\
\text { 1. SC 7-8 } \\
\text { 2. BASC-2 } \\
\text { 3. YRBS } \\
\mathrm{n}=12\end{array}$ \\
\hline $8^{\text {th }}$ Grade & $\begin{array}{l}\text { COHORT D } \\
\text { 1. SC 7-8 } \\
\text { 2. BASC-2 } \\
\text { 3. YRBS } \\
\mathrm{n}=50\end{array}$ & $\begin{array}{l}\text { COHORT C } \\
\text { 1. SC 7-8 } \\
\text { 2. BASC-2 } \\
\text { 3. YRBS } \\
\mathrm{n}=56\end{array}$ & $\begin{array}{l}\text { COHORT C } \\
\text { 1. SC 7-8 } \\
\text { 2. BASC-2 } \\
\text { 3. YRBS } \\
\mathrm{n}=37\end{array}$ & $\begin{array}{l}\text { COHORT B } \\
\text { 1. SC 7-8 } \\
\text { 2. BASC-2 } \\
\text { 3. YRBS } \\
\mathrm{n}=41\end{array}$ & $\begin{array}{l}\text { COHORT B } \\
\text { 1. SC 7-8 } \\
\text { 2. BASC-2 } \\
\text { 3. YRBS } \\
\mathrm{n}=35\end{array}$ \\
\hline $9^{\text {th }}$ Grade & NA & NA & NA & $\begin{array}{l}\text { COHORT C } \\
\text { 1. SC 7-8 } \\
\text { 2. BASC-2 } \\
\text { 3. YRBS } \\
\mathrm{n}=2\end{array}$ & $\begin{array}{l}\text { COHORT C } \\
\text { 1. SC 7-8 } \\
\text { 2. BASC-2 } \\
\text { 3. YRBS } \\
\mathrm{n}=9\end{array}$ \\
\hline Total & $\mathrm{n}=261$ & $\mathrm{n}=304$ & $\mathrm{n}=228$ & $\mathrm{n}=80$ & $\mathrm{n}=117$ \\
\hline
\end{tabular}

Note. Shading indicates one cohort over time. ${ }^{\text {a SC }} 5-6$ denotes School Climate scales for fifth and sixth grade from the Developmental Studies Center: Child Development Project

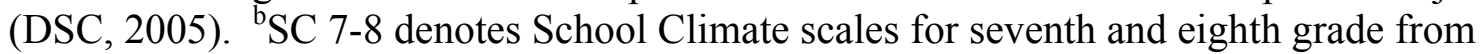
the Developmental Studies Center: Child Development Project (DSC, 2005). ${ }^{\mathrm{c}}$ BASC-2 denotes Behavior Assessment System for Children, Second Edition: Self-Report of Personality (BASC-2: SRP; Reynolds \& Kamphaus, 2004). ${ }^{\mathrm{d}}$ YRBS denotes Youth Risk Behavior Survey from the Center for Disease Control and Prevention (YRBS; CDC, 2011). 


\section{Research Participants}

Participants included a total of 510 students (274 girls and 236 boys). Of this total, $43 \%$ of participants were Caucasian, $<1 \%$ were African American, $<1 \%$ were Hispanic/Latino, $<1 \%$ were Asian, $1 \%$ were multiracial, and $55 \%$ did not provide information about race/ethnicity. According to the Illinois State Board of Education (2014), approximately $90 \%$ of students in this school district were Caucasian (https://illinoisreportcard.com). In terms of socioeconomic status, $59 \%$ of the participants did not have free or reduced lunch, $4 \%$ had reduced lunch, $15 \%$ had free lunch, and $22 \%$ had undocumented lunch status. For disability status, $77 \%$ of participants did not have a disability, $1 \%$ had a disability, and $22 \%$ had unknown disability status. Taken together, this sample was a largely homogenous group for which there were many missing data. As a result, it was not possible to examine race/ethnicity, socioeconomic status, or disability status as predictors in this study. To recruit participants, researchers attended school registration sessions to inform parents about the study and obtain parent consent. Researchers delivered parent consent forms to the schools for students to bring to their parents. For data collection, researchers scheduled student survey sessions with school principals. Researchers informed participating students about the study and obtained student assent at the beginning of survey sessions.

\section{Predictor Variables}

\section{Social Climate Perceptions}

To assess social climate perceptions, students completed selected scales from the Developmental Studies Center: Child Development Project (DSC, 2005). Students filled 
out social climate scales corresponding to their grade levels (i.e., grades 5-6 vs. 7-8). Students rated their school and classroom supportiveness (i.e., "the degree to which students feel their classmates are supportive, helpful, and mutually concerned"), autonomy and influence at school (i.e., "the opportunity to participate in classroom planning and decision-making"), and sense of school community (i.e., "the degree to which students feel their school as a whole is supportive, welcoming, and safe") (DSC, 2005, pp. 1-2). The DSC (2005) found that internal consistency reliabilities were .87 for grades 5-6 and .82 for grades 7-8. For the present study, internal consistency reliabilities ranged from .80 to .89 . Items that were consistent across grade level scales were included in the analyses to maintain a longitudinal view of students' perceived social climate. I used these data to examine students' perceived social climate over time in relation to their functioning.

\section{Outcome Variables}

Students completed self-report questionnaires measuring their internalizing problems, personal adjustment, and risky behavior. Students in grades 5-9 filled out questionnaires about their internalizing problems and personal adjustment and students in grades 7-9 also completed the risky behavior survey. I conducted a review of students' academic records to obtain their math and reading scores on curriculum-based measures (CBM) over time. I examined students' internalizing problems, personal adjustment, risky behavior, and academic performance over time in relation to their perceived social climate. 


\section{Internalizing Problems}

To assess adolescents' internalizing problems, Merrell (2010) recommended the use of self-report measures. The Behavior Assessment System for Children, Second Edition, Self-Report of Personality (BASC-2: SRP-C and SRP-A; Reynolds \& Kamphaus, 2004) is an empirically developed broadband measure that includes an internalizing composite. Merrell (2010) stated that the "SRP-C and SRP-A of the BASC2 are exemplary child and adolescent self-report instruments in every respect...[these instruments] will continue to be among the most widely used child and adolescent selfreport measures and probably are as close to being a 'standard work' for school-based assessment" (p. 213). From 2002 to 2004, standardization of the BASC-2: SRP for general norms included 3,400 children and adolescents between the ages of 8 to 18 years with demographics reflecting the 2001 U.S. population demographics (Reynolds \& Kamphaus, 2004). For the present study, I used the BASC-2: SRP (Reynolds \& Kamphaus, 2004) to assess students' internalizing problems. On the BASC-2: SRP, internalizing problems include anxiety, depression, social stress, sense of inadequacy, locus of control, and atypicality (Reynolds \& Kamphaus, 2004). For internalizing problems, internal consistency reliabilities for the standardization sample were high at .96 , and test-retest reliabilities were also high at .82 (Reynolds \& Kamphaus, 2004). The BASC-2:SRP uses $t$-scores, which have a mean of 50 and a standard deviation of 10 . For problem scales (i.e., internalizing problems), students with $t$-scores below 60 are considered as being within the typical range, students with $t$-scores between 60 to 69 are considered in the at-risk range, and students with $t$-scores at 70 or above are considered in 
the clinically significant range (Reynolds \& Kamphaus, 2004). For my sample, the mean was 50.47 and standard deviation was 12.07. Thus, most students were within normal limits. Students completed the BASC-2: SRP within 20 minutes.

\section{Personal Adjustment}

Personal adjustment includes self-esteem, self-reliance, interpersonal relations, and relations with parents (Reynolds \& Kamphaus, 2004). I used the personal adjustment composite on the BASC-2: SRP to assess these areas for students (Reynolds \& Kamphaus, 2004). During standardization, the personal adjustment composite on the BASC-2: SRP had internal consistency reliability of .88 for children (ages 8 to 11 years) and .90 for adolescents (ages 12 to 14 years) (Reynolds \& Kamphaus, 2004). Test-retest reliability for personal adjustment was .75 for children and .74 for adolescents in the standardization sample (Reynolds \& Kamphaus, 2004). The BASC-2:SRP uses $t$-scores, which have a mean of 50 and a standard deviation of 10 . For adaptive scales, students with $t$-scores above 40 are considered as being within the typical range, students with $t$ scores between 31 to 40 are considered in the at-risk range, and students with $t$-scores at 30 or below are considered in the clinically significant range (Reynolds \& Kamphaus, 2004). For my sample, the mean was 49.74 and standard deviation was 11.30 . Thus, most students were within normal limits. Students completed the BASC-2: SRP within 20 minutes.

\section{Risky Behavior}

Students in grades 7-9 completed a condensed version of the Center for Disease Control and Prevention's (CDC) Youth Risk Behavior Survey (YRBS, 2011). The CDC 
(2011) developed the YRBS to monitor students' health-risk behaviors. The CDC conducted two test-retest reliability studies and found that the YRBS had high reliability for 75 percent of the items in 1992. Additionally, in 2000, prevalence estimates for 80 percent of the items did not differ significantly (CDC, 2004). To assess students' risky behavior, students responded to items about drinking alcohol, smoking cigarettes, carrying weapons, and fighting. Students completed the YRBS in less than 10 minutes.

\section{Academic Achievement}

To assess students' academic functioning, I conducted a review of students' school records to find their scores on curriculum-based measures in math and reading. Specifically, I used students' scores on AIMSweb: Math Concepts and Applications (MCAP), Math Computation (MCOMP), Reading Fluency (RCBM), and Reading Comprehension (MAZE). The schools administered these measures to all students.

\section{Procedure}

Researchers contacted school principals to discuss student recruitment and data collection procedures. Researchers sent consent forms home with students to give to parents, and they attended school registration sessions to explain the study and obtain parent consent. Although school principals approved this type of recruitment, it might have limited the number of participants in the study. Specifically, it is possible students did not give the consent forms to parents, or parents did not provide consent due to them not having the opportunity to speak with researchers in person. For the registration sessions, it is plausible that parents were overwhelmed with other school information or did not have enough time to speak with researchers who were stationed at the last table of 
the registration session. It is also possible that some parents did not attend these registrations sessions, so they did not have the opportunity to participate in the study.

Researchers scheduled student survey sessions with school principals. At these survey sessions, researchers read assent scripts aloud while students read the forms silently. Researchers individually answered students' questions throughout the session. Surveys included selected social climate scales from the Developmental Studies Center: Child Development Project (DSC, 2005), the Behavior Assessment System for Children, Second Edition: Self-Report of Personality (BASC-2: SRP; Reynolds \& Kamphaus, 2004), and the adapted Youth Risk Behavior Survey (YRBS) from the Center for Disease Control and Prevention (CDC, 2011). Researchers counterbalanced the order of these questionnaires. Researchers debriefed students following survey sessions. Researchers obtained students' math and reading scores from school records. 


\section{CHAPTER IV}

\section{ANALYSIS OF THE DATA}

The following research questions guided my analysis of the data: (1) Do grade level and gender predict students' initial school climate perceptions? (2) Do middle school students' school climate perceptions change over time? (3) Are students' school climate perceptions concurrently related to their academic, behavioral, and socialemotional functioning? (4) Are there unidirectional effects between students's school climate perceptions and functioning (i.e., academic, behavioral, and social-emotional)?

\section{Question 1: Do Grade Level and Gender Predict Students' Initial School Climate Perceptions?}

For the first question, I predicted that students in higher grades (i.e., seventh and eighth) would have more negative initial climate perceptions than students in lower grades (i.e., fifth and sixth) and that girls would have more positive initial climate perceptions than boys (see Figure 5). To test these hypotheses, I used several models to explore relations between school climate, grade level, gender, and semester effects (i.e., fall vs. spring). Specifically, I used an ANOVA that treated grade as a nominal variable, an ANCOVA with grade as a covariate to treat it as an interval variable, an ANCOVA with grade and semester effects as covariates to control for the effects of time on climate perceptions, and a Pearson product-moment correlation to examine the relation between grade level and perceived climate. The correlation best represented the data. 


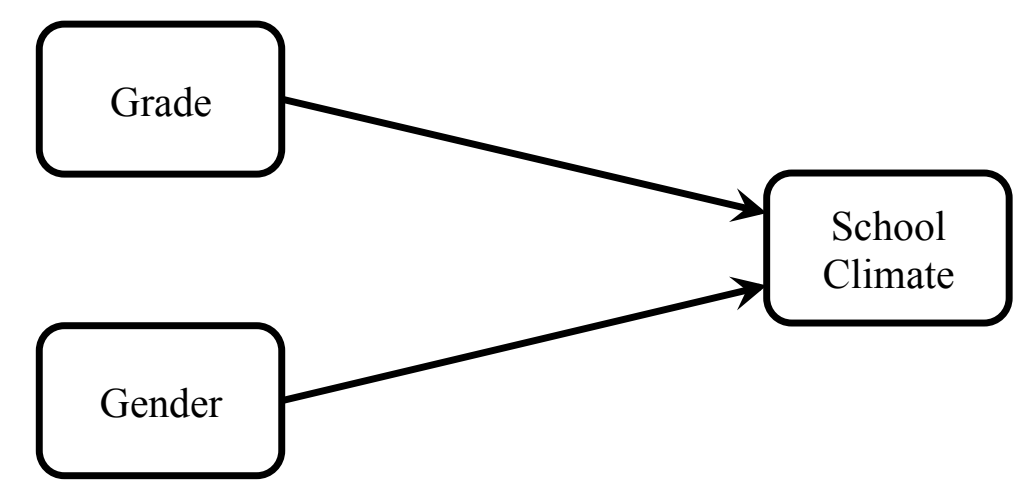

Figure 5. Question 1: Hypothesized predictors (i.e., grade and gender) of school climate.

Results partially supported my hypotheses. Students' grade level was related to their initial perceptions of climate. There was a small, linear, negative correlation between grade level and initial school perceptions, $r(477)=-.12, p=.007$. As predicted, findings indicated that students in higher grade levels had more negative climate perceptions than those in younger grades. Results showed no evidence of gender or time of year on students' initial climate perceptions. Figure 6 displays results of analyses.

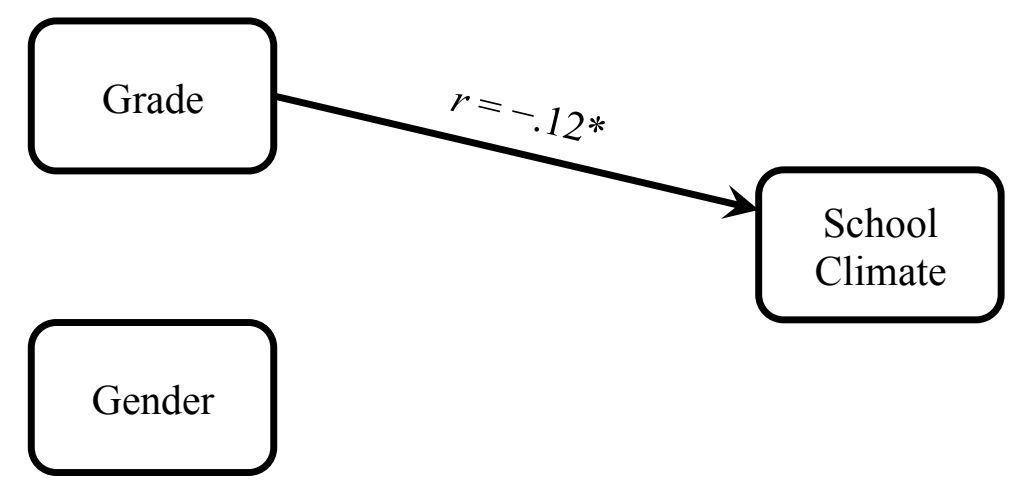

Figure 6. Question 1: Results for predictors (i.e., grade and gender) of school climate. The solid arrow and asterisk represent a significant correlation. 


\section{Question 2: Do Middle School Students' School Climate Perceptions Change Over}

Time?

I predicted that individual students' climate perceptions would become more negative as they entered higher grades. Figure 7 displays the hypothesized changes in school climate perceptions over time.

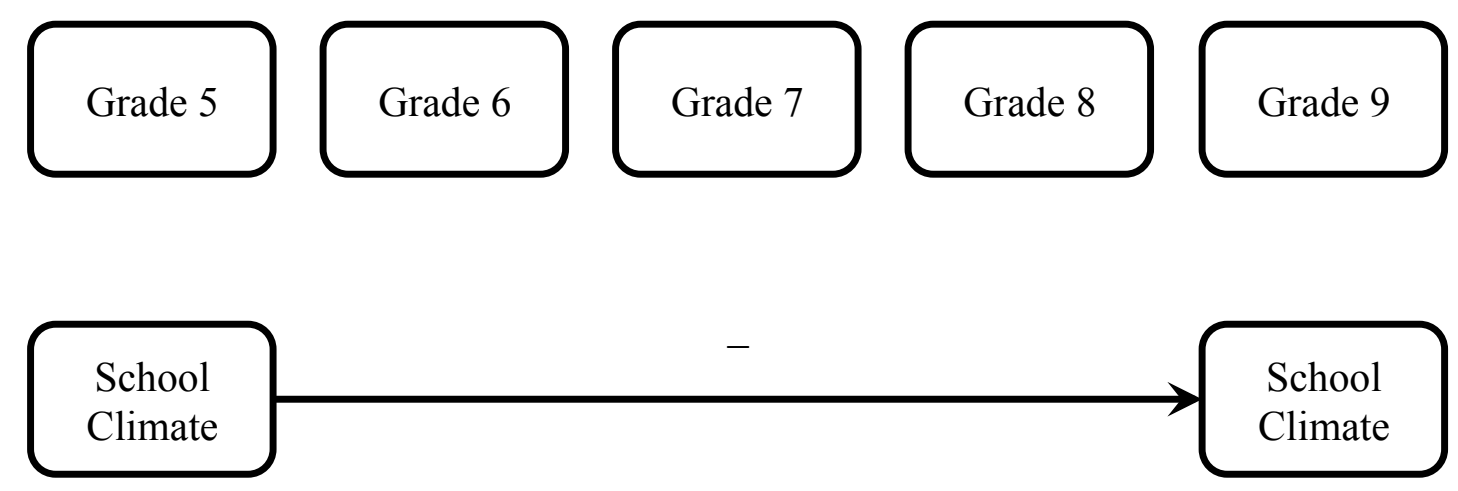

Figure 7. Question 2: Hypothesized changes in school climate over time

I used hierarchical linear modeling (HLM), specifically a Random Intercepts Model, to test this hypothesis (Raudenbush \& Bryk, 2002). One advantage of HLM over repeated measures ANOVA is that it does not remove students with missing data from the analyses. I used several models, which are described in Table 2, to examine how students' climate perceptions would change as a function of grade level and time. In the results below, the $t$-tests are reported without degrees of freedom and without significance values because there is, at present, no non-controversial method of estimating them in random effects models (Bates, 2005). Therefore, $t$-values with 
absolute values greater than 2 are considered statistically significant, which is a conservative threshold for a sample size of 487 participants.

The model building sequence proceeded as shown in Table 2. As a baseline, a Random Intercepts Model allowed for each student to have his or her own intercept, which represented each student's mean rating of school climate. In the second model, a fixed linear effect of time was added to see if students' ratings of school climate changed over time. Results suggested that, on average, student ratings of school climate declined over time, $\beta_{10}=-0.09, t=-4.38$. Figure 8 shows the changes in school climate over time. In Model 3, the slope associated with time was allowed to vary from student to student, as seen in Figure 9, which resulted in the slopes having little variability. As seen in Table 2, including random slopes in the model did not improve model fit significantly. Quadratic effects of time and cohort effects were evaluated but neither was statistically significant. Thus, of all the models considered, Model 2 was the most parsimonious representation of the data. The overall interpretation of these analyses is that students perceived a decrease in school climate over time, but the effect was small. On a scale of 1 to 5 , the average rating at Grade 5 was 3.49 , which dropped slightly to 3.22 at Grade 9 . 


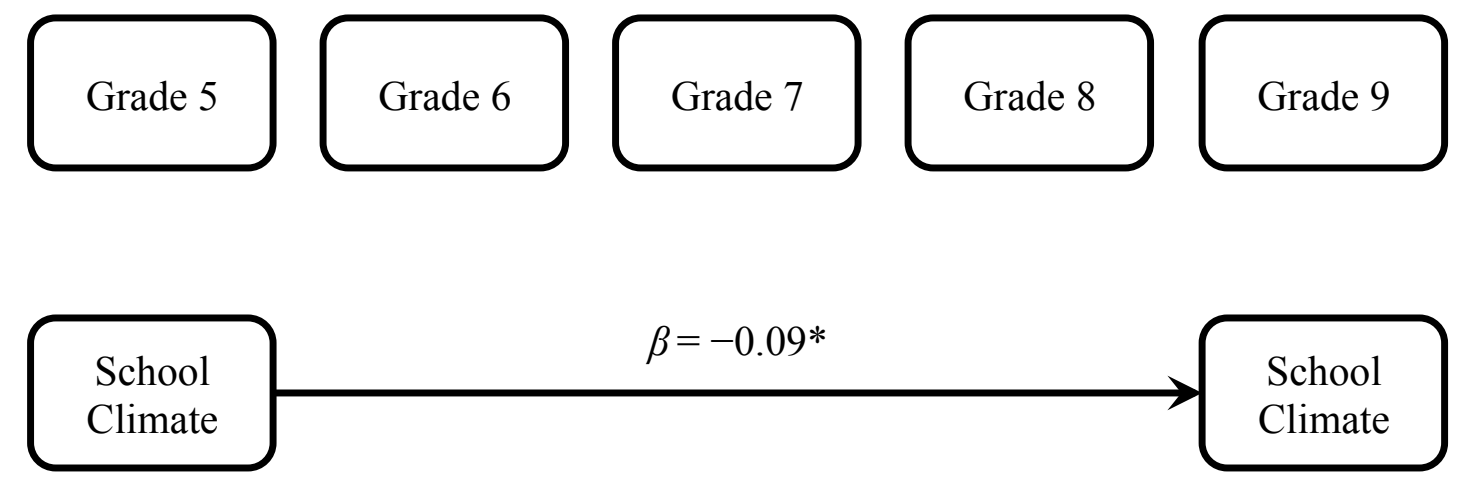

Figure 8. Question 2: Results for changes in school climate over time. The solid arrow and asterisk represent a significant finding with school climate becoming more negative over time.

Table 2

Hierarchical Linear Modeling of School Climate Over Time

\begin{tabular}{lllll}
\hline Model & Equation & $\chi^{2}$ & $d f$ & $p$ \\
\hline 1. Random intercepts & $Y_{t i}=\left(\beta_{00}+u_{0 i}\right)+e_{t i}$ & & & \\
2. Fixed linear effect of time & $Y_{t i}=$ Model 1+ $\beta_{10}$ Time $_{t i}$ & 22.00 & 1 & $<.001$ \\
3. Random linear effect of time & $Y_{t i}=$ Model 2 $+u_{1 i}$ Time $_{t i}$ & 4.56 & 2 & .10 \\
4. Fixed quadratic effect of time & $Y_{t i}=$ Model 2 $+\beta_{20}$ Time $_{t i}^{2}$ & 1.98 & 1 & .16 \\
5. Fixed effect of cohort & $Y_{t i}=$ Model 2 $+\beta_{30}$ Cohort $_{i}$ & 1.46 & 1 & .23 \\
\hline
\end{tabular}




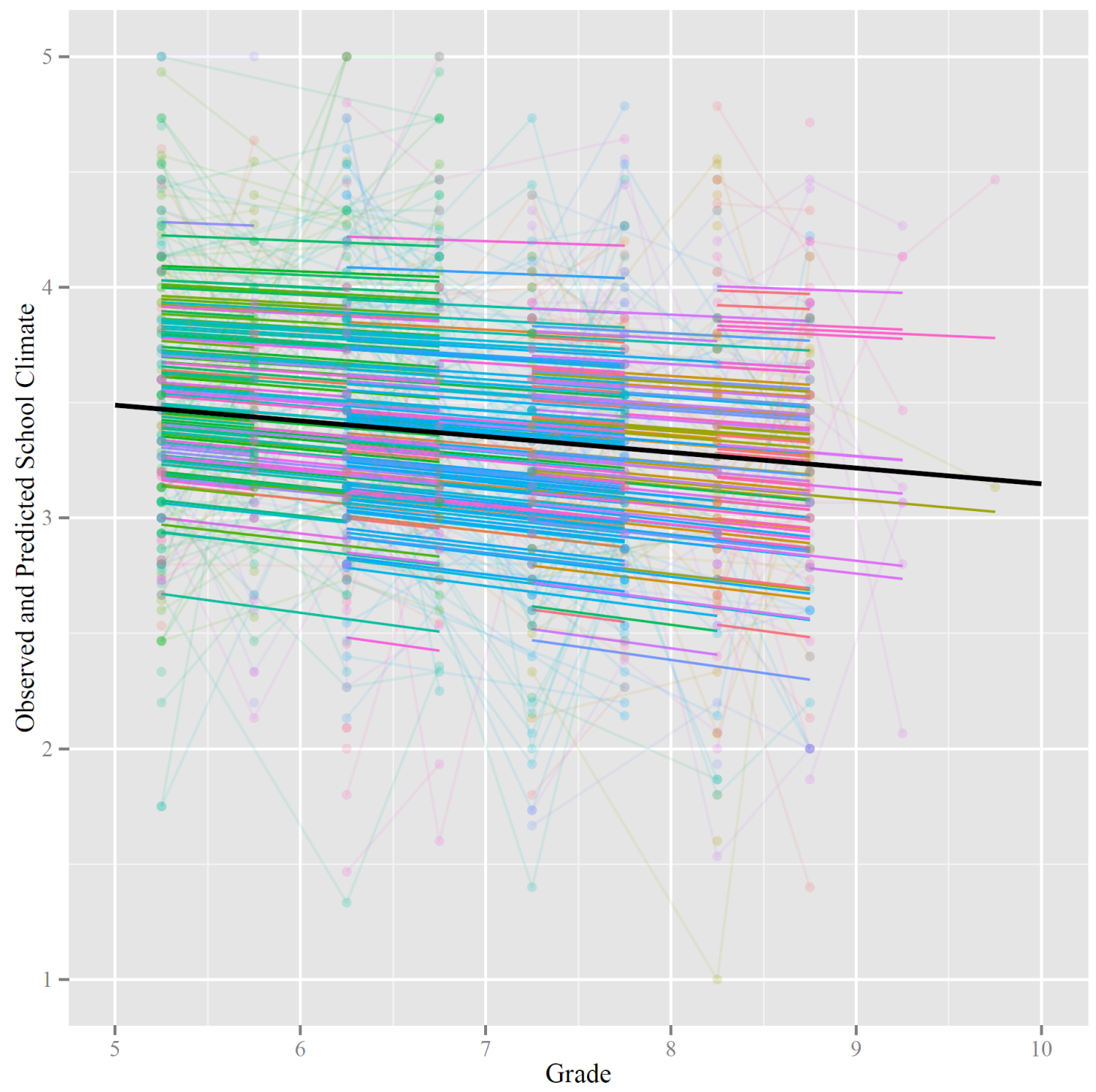

Figure 9. Question 2: Results for observed and predicted changes in school climate across grades. Results revealed that students' school climate perceptions became more negative as they entered higher grade levels. Dots indicate students' observed school climate scores. The thick line in the center represents the average slope of school climate scores across grades. The thinner lines show students' predicted school climate scores when all students have the same slope. 


\section{Question 3: Are Students' School Climate Perceptions Concurrently Related to Their Academic, Social-Emotional, and Behavioral Functioning?}

I hypothesized that students with more positive climate perceptions would have higher reading and mathematics scores, engage in less risky behavior, have fewer internalizing problems, and have better personal adjustment (see Figure 10). To test these hypotheses, I used a Random Intercepts Model. Findings partially supported these hypotheses.

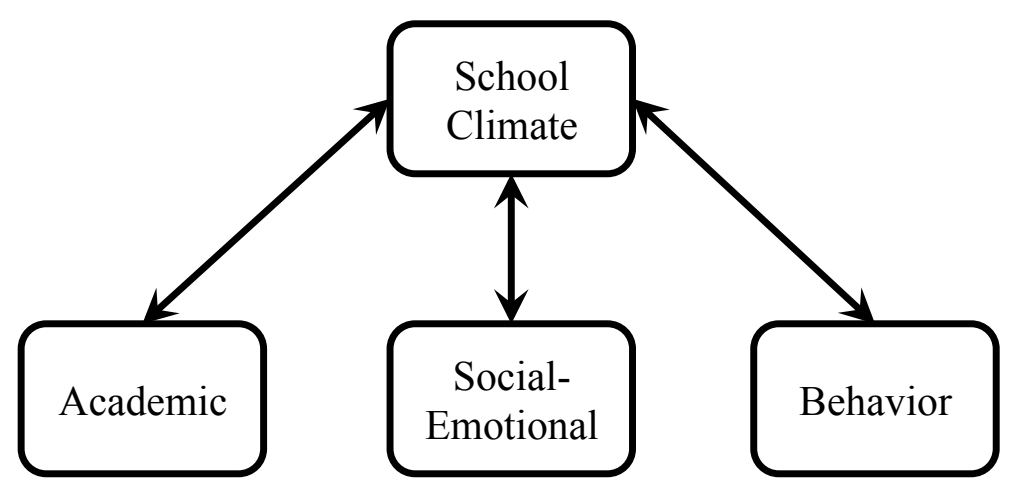

Figure 10. Question 3: Hypothesized concurrent relations between school climate and students' academic, social-emotional, and behavioral functioning at each assessment time.

For academic functioning, students' climate perceptions were positively related to their math computation scores, $t=2.76$. Every one-unit increase in climate perceptions was related to math scores increasing by $1.04 t$-scores. There was no evidence of relations between students' school climate perceptions and their math problem solving scores or reading comprehension and fluency scores. Figure 11 displays relations between students' climate perceptions and academic functioning. 


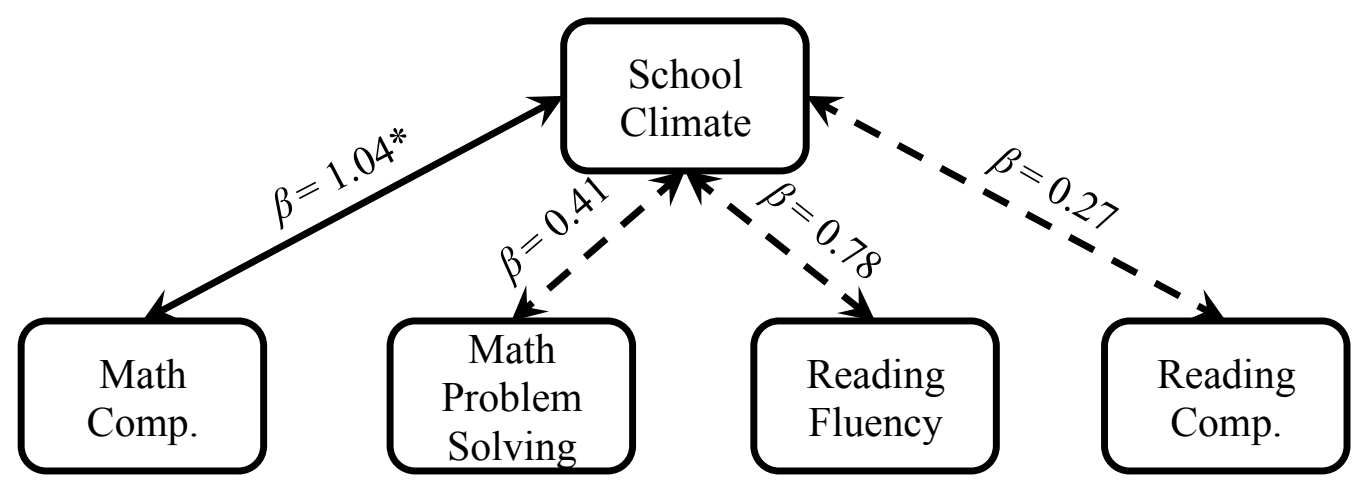

Figure 11. Question 3: Results for concurrent relations between school climate and students' academic functioning. Solid arrows and asterisks represent significant relations. Dashed arrows show non-significant results.

As predicted, students' perceptions of climate were inversely related to their risky behavior such that students with more positive climate perceptions engaged in fewer risky behaviors. Specifically, more positive climate perceptions were related to less fighting $(t=-3.76)$, weapon carrying $(t=-3.43)$, alcohol use $(t=-4.17)$, and cigarette use $(t=-2.46)$. Figure 12 shows relations between students' climate perceptions and risky behavior. 


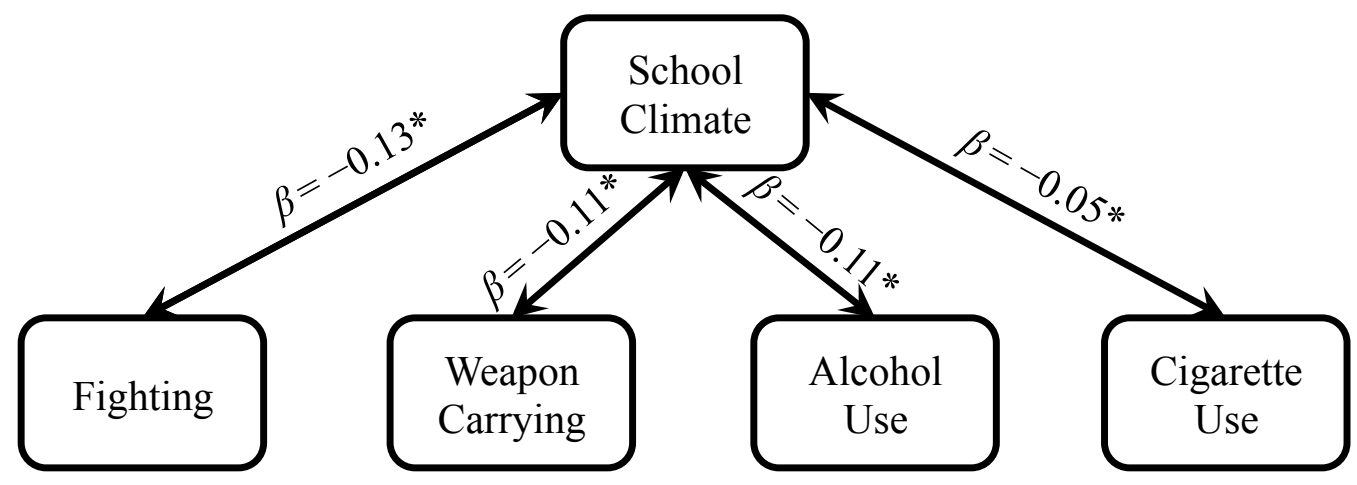

Figure 12. Question 3: Results for concurrent relations between school climate and students' behavioral functioning. Solid arrows and asterisk represent significant relations. Dashed arrows show non-significant findings.

Consistent with hypotheses for social-emotional functioning, students' perceptions of climate were inversely related to their internalizing problems $(t=-9.54)$ and positively related to their personal adjustment $(t=10.51)$. For every one-unit increase in school climate perceptions, students' internalizing problems decreased by $5.83 t$-scores and their personal adjustment increased by $6.41 t$-scores. The average tscore for internalizing problems was 50.28 and the average t-score for personal adjustment was 49.74 with these averages suggesting that students in the study had internalizing problems and personal adjustment comparable to typically developing peers. These data show that a student who displayed the average level of internalizing problems $(\bar{x}=50.28)$ and personal adjustment $(\bar{x}=49.74)$ would be predicted to be in the at-risk range if he/she had a two-point decrease in their climate perceptions and in the clinically 
significant range with a four-point decrease in perceived climate. Figure 13 shows relations between students' climate perceptions and social-emotional outcomes.

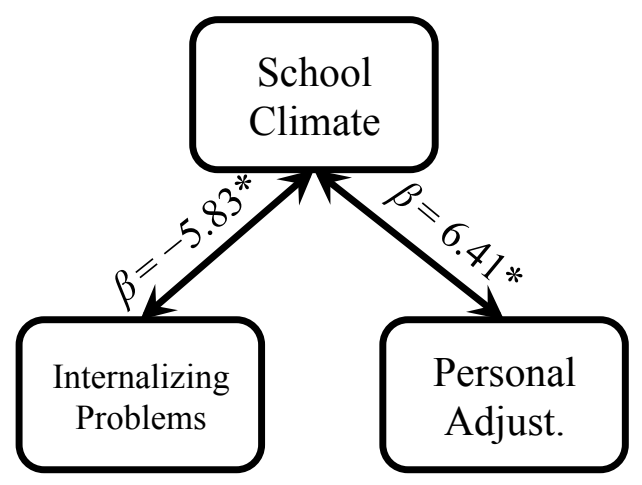

Figure 13. Question 3: Results for concurrent relations between school climate and students' social-emotional functioning. Solid arrows and asterisks represent significant relations. Dashed arrows show non-significant findings. 


\section{Question 4: Are There Unidirectional Effects Between Students' School Climate}

\section{Perceptions and Academic, Social-Emotional, and Behavioral Functioning?}

For exploring the direction of effects, I hypothesized there would be unidirectional relations such that students' climate perceptions would predict their future academic, behavioral, and social-emotional functioning whereas these areas of functioning would not predict future perceptions of school climate (see Figure 14). To test this hypothesis, I used Hierarchical Linear Modeling.

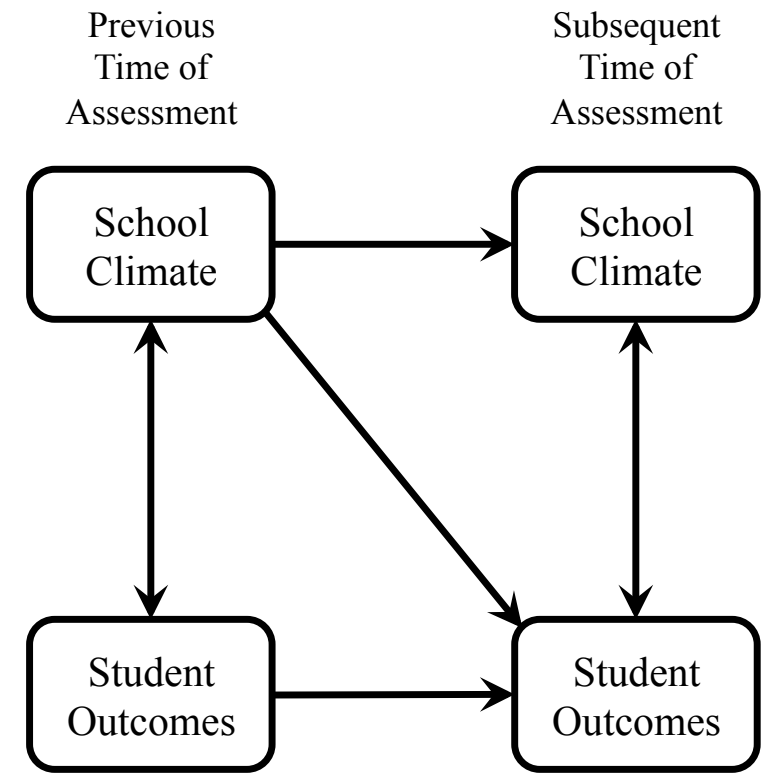

Figure 14. Question 4: Hypothesized unidirectional relations with students' previous school climate perceptions predicting their subsequent academic, social-emotional, and behavioral functioning.

For students' academic functioning, findings partially supported hypotheses. As expected, students' past academic performance predicted their future academic 
performance in all academic areas (i.e., math computation, $t=18.44$; math problem solving, $t=11.10$; reading comprehension, $t=20.20$; reading fluency $t=26.61)$. In contrast to hypotheses, previous climate perceptions did not predict future academic performance. Consistent with expectations, there was no evidence that students' previous academic functioning predicted their future climate perceptions. As mentioned, there were concurrent relations between students' school climate perceptions and math computation (see Question 3). Figures 15 through 18 display relations between students' climate perceptions and academic functioning over time.

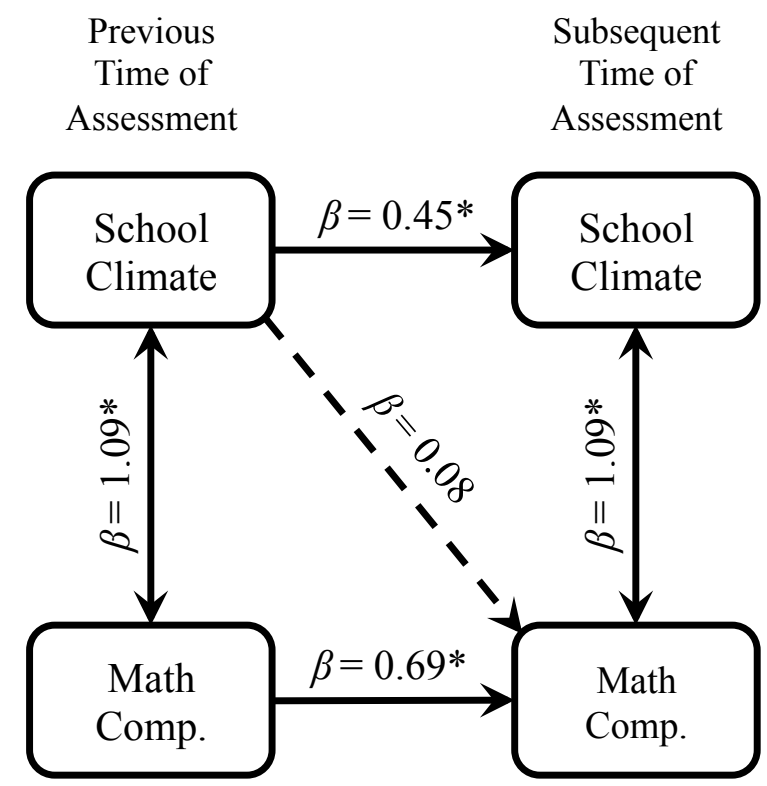

Figure 15. Question 4: Results for unidirectional relations between students' previous school climate perceptions and their future math computation performance. Solid arrows and asterisks represent significant relations. Dashed arrows show non-significant findings. 


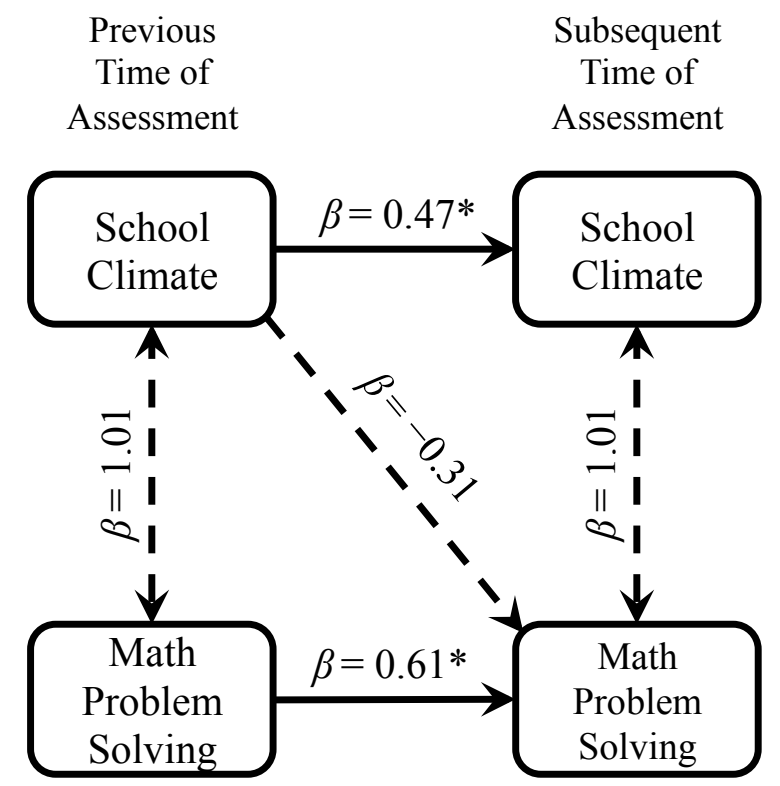

Figure 16. Question 4: Results for unidirectional relations between students' previous school climate perceptions and their future math problem solving performance. Solid arrows and asterisks represent significant relations. Dashed arrows show non-significant findings. 
Time 1

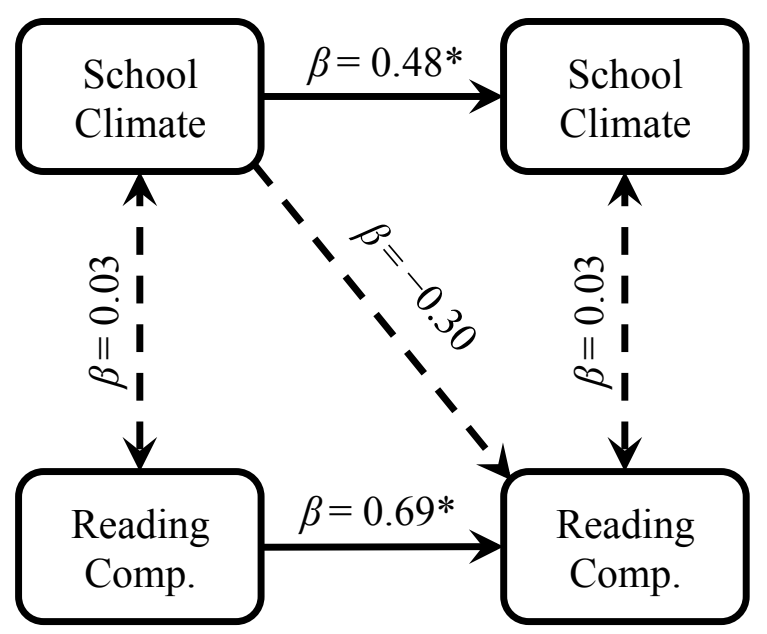

Figure 17. Question 4: Results for unidirectional relations between students' previous school climate perceptions and their future reading comprehension performance. Solid arrows and asterisks represent significant relations. Dashed arrows show non-significant findings. 


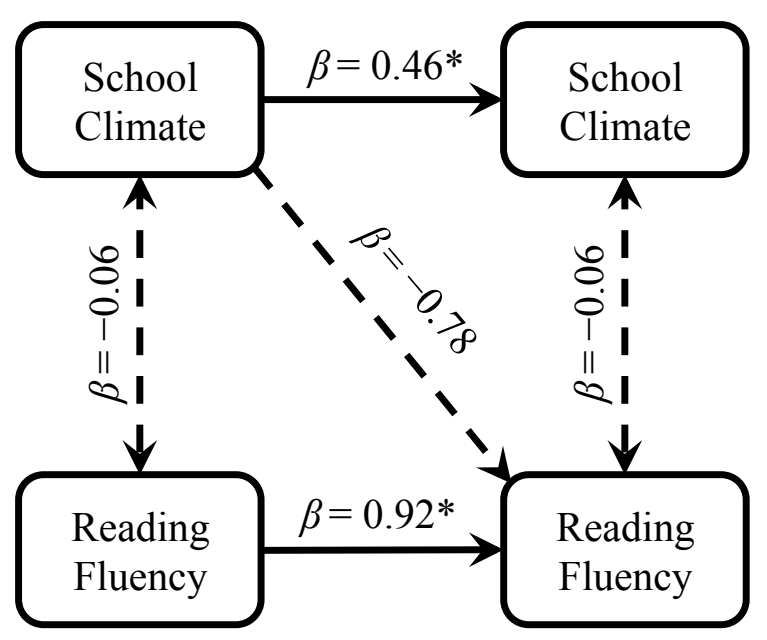

Figure 18. Question 4: Results for unidirectional relations between students' previous school climate perceptions and their future reading fluency performance. Solid arrows and asterisks represent significant relations. Dashed arrows show non-significant findings.

In regards to risky behavior, results partially supported hypotheses. Students' past school climate perceptions predicted their future fighting $(t=2.00)$ and future cigarette use $(t=2.05)$ but not future alcohol use or weapon carrying. Unexpectedly, the previous carrying of weapons predicted future school climate perceptions, $t=2.52$. As anticipated, all previous risky behavior predicted future risky behavior (i.e., carrying weapons, $t=6.51$; fighting, $t=7.02$; smoking cigarettes, $t=6.82$; drinking alcohol, $t=2.12$ ). Past school climate perceptions also predicted future climate perceptions across the analyses for each of the risky behavior outcome measures (i.e., carrying 
weapons, $t=7.99$; fighting, $t=7.88$; smoking cigarettes, $t=7.91$; drinking alcohol, $t=6.86)$. As described, there were concurrent relations between climate perceptions and risky behavior (see Question 3). Figures 19 through 22 show relations between students' climate perceptions and risky behavior over time.

Time $1 \quad$ Future

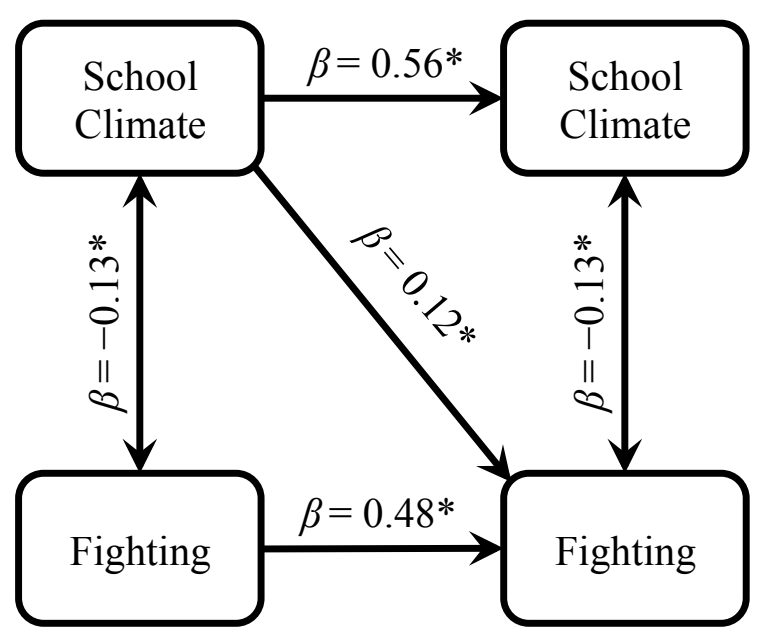

Figure 19. Question 4: Results for unidirectional relations between students' previous school climate perceptions and their future fighting. Solid arrows and asterisks represent significant relations. Dashed arrows show non-significant findings. 
Time $1 \quad$ Future

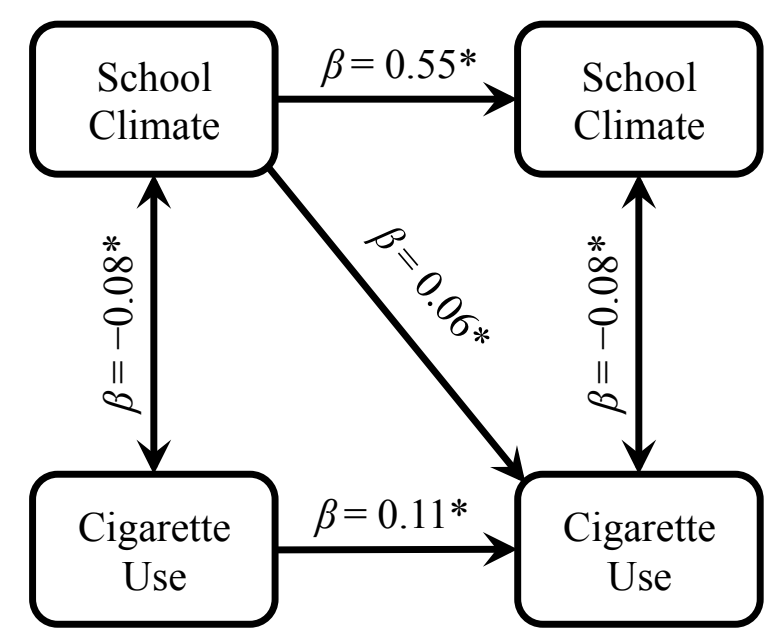

Figure 20. Question 4: Results for unidirectional relations between students' previous school climate perceptions and their future cigarette use. Solid arrows and asterisks represent significant relations. Dashed arrows show non-significant findings. 
Time 1

Future

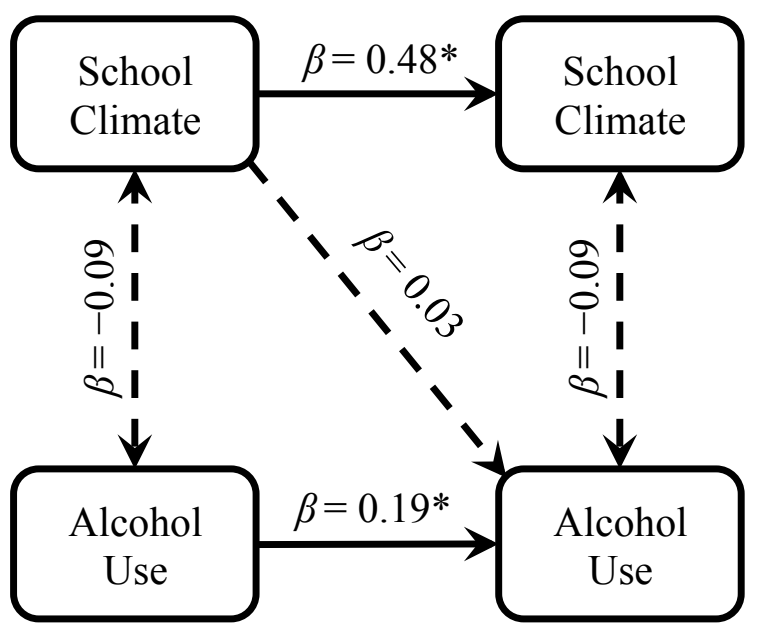

Figure 21. Question 4: Results for unidirectional relations between students' previous school climate perceptions and their future alcohol use. Solid arrows and asterisks represent significant relations. Dashed arrows show non-significant findings. 
Time 1

Future

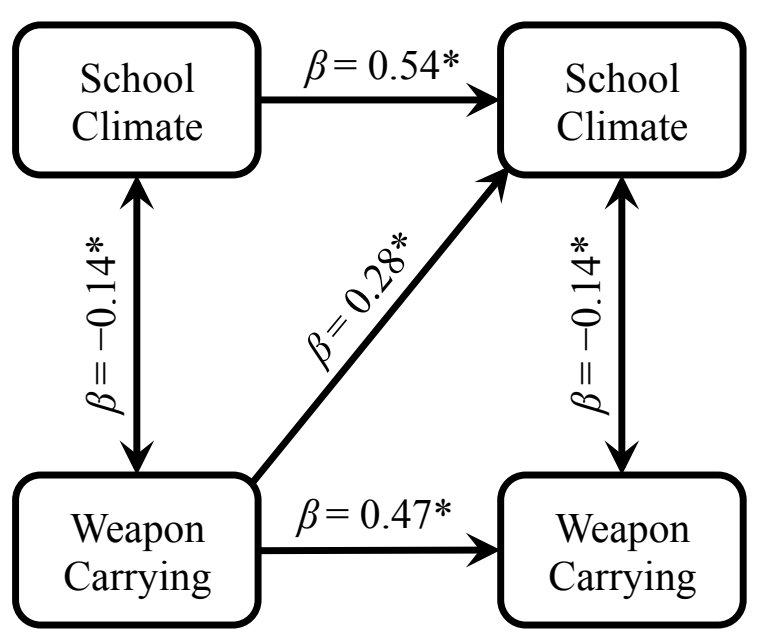

Figure 22. Question 4: Results for unidirectional relations between students' previous school climate perceptions and their future carrying of weapons. Solid arrows and asterisks represent significant relations. Dashed arrows show non-significant findings.

For social-emotional functioning, results provided partial support for hypotheses. As predicted, students' previous internalizing problems and personal adjustment did not predict future climate perceptions. As expected, previous social-emotional functioning predicted future social-emotional functioning (i.e., internalizing problems, $t=14.50$; personal adjustment, $t=10.25)$. Past climate perceptions predicted future climate perceptions for each of the analyses (i.e., internalizing problems, $t=2.72$; personal adjustment, $t=3.30$ ). However, previous climate perceptions did not predict future internalizing problems or personal adjustment. As explained, climate perceptions were concurrently related to social-emotional functioning (see Question 3). Figures 23 and 24 
display relations between school climate perceptions and social-emotional functioning over time.

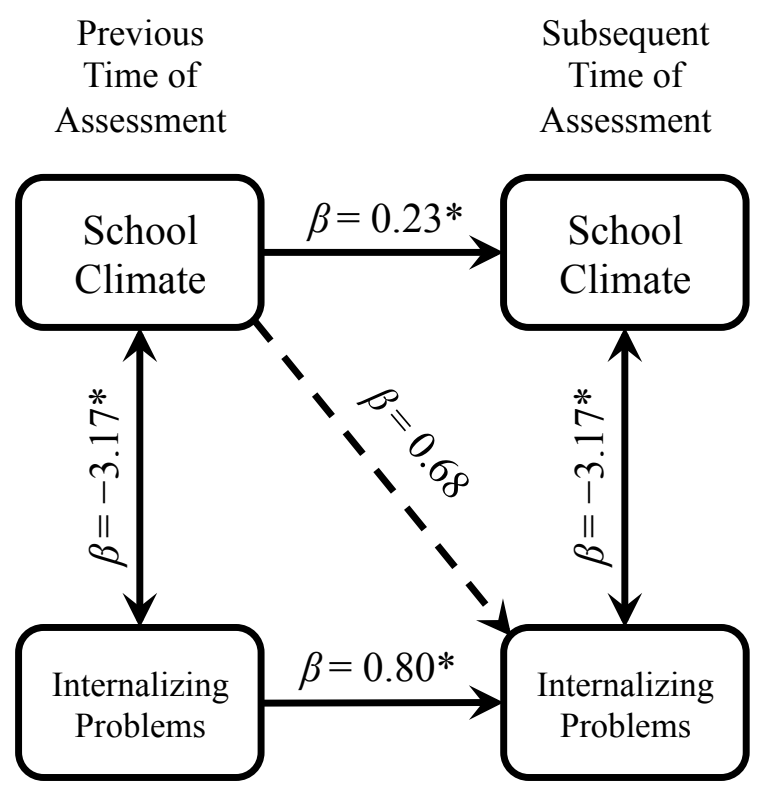

Figure 23. Question 4: Results for unidirectional relations between students' previous school climate perceptions and their future internalizing problems. Solid arrows and asterisks represent significant relations. Dashed arrows show non-significant findings. 


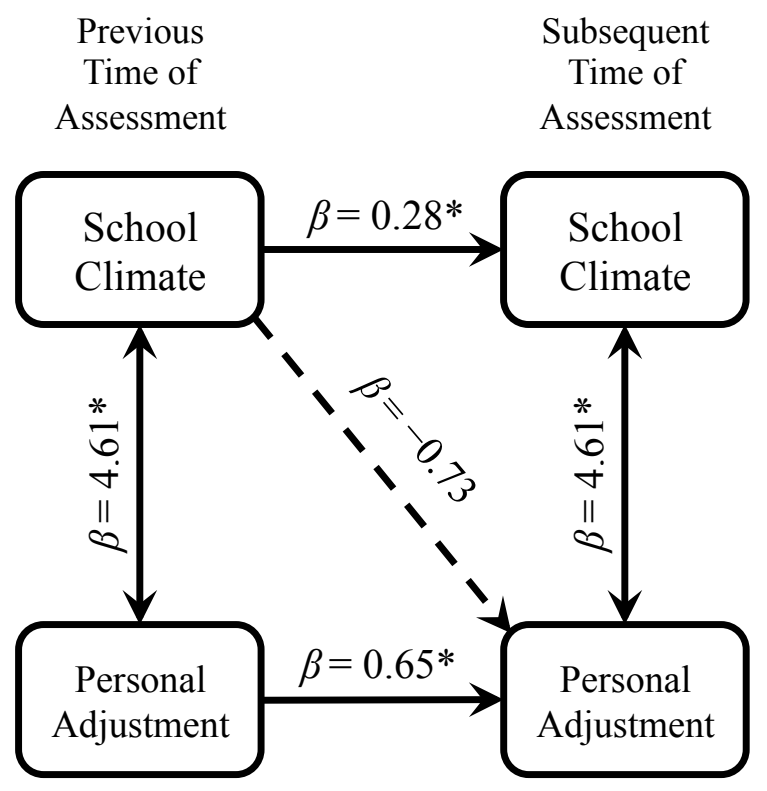

Figure 24. Question 4: Results for unidirectional relations between students' previous school climate perceptions and their future personal adjustment. Solid arrows and asterisks represent significant relations. Dashed arrows show non-significant findings.

Overall, school climate perceptions predicted future climate perceptions in each of the analyses and functioning predicted future performance. Climate perceptions predicted future fighting and cigarette use but not other risky behaviors, social-emotional functioning, or academic performance. As described, there were concurrent relations between climate perceptions and social-emotional functioning, risky behavior, and math performance (see Question 3).

\section{Post-Hoc Analyses}

After examining changes in students' school climate perceptions, I became interested in analyzing changes in students' functioning over time. To examine these 
changes, I used hierarchical linear modeling (HLM), a Random Intercepts Model (Raudenbush \& Bryk, 2002).

For social-emotional functioning, there were quadratic effects for students' internalizing problems $\left(\beta_{10}=.79, t=2.77\right)$ and personal adjustment $\left(\beta_{10}=-0.60, t=\right.$ $-2.00)$. These findings indicated that students experienced slight improvement in socialemotional functioning until seventh grade and then experienced increases in socialemotional problems (i.e., increases in internalizing problems and decreases in personal adjustment). Figures 25 and 26 show changes in students' internalizing problems and personal adjustment across grade levels. Further, there were time effects such that students experienced more internalizing problems $\left(\beta_{10}=0.52, t=2.67\right)$ and lower levels of personal adjustment $\left(\beta_{10}=-0.60, t=-3.18\right)$ during the 2013-2014 school year compared to earlier semesters regardless of their grade level. 


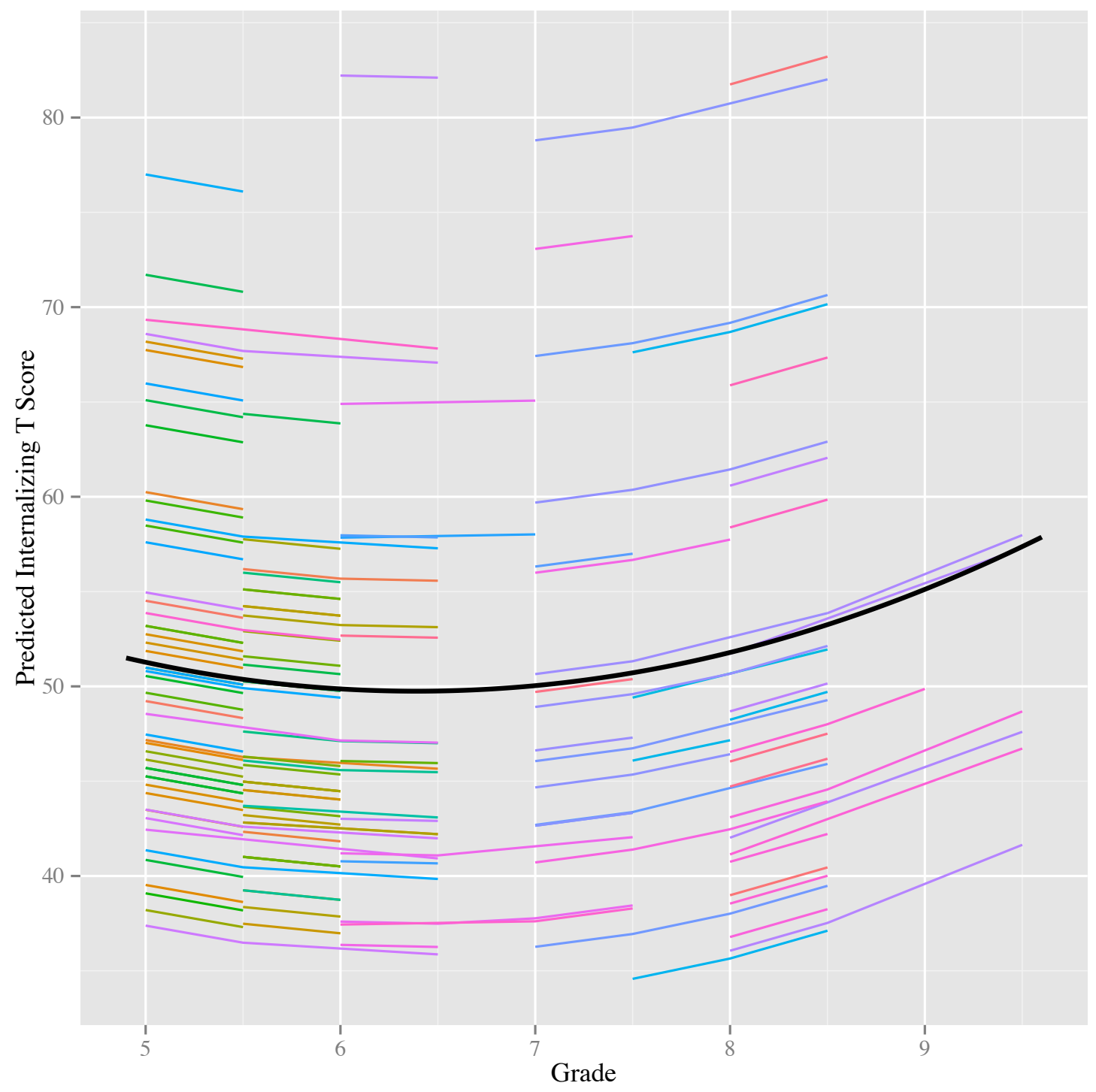

Figure 25. Post-Hoc: Results for predicted changes in students' internalizing problems across grades. The thick line in the center represents the average slope of school climate scores across grades. The thinner lines show students' predicted internalizing problems when all students have the same slope. 


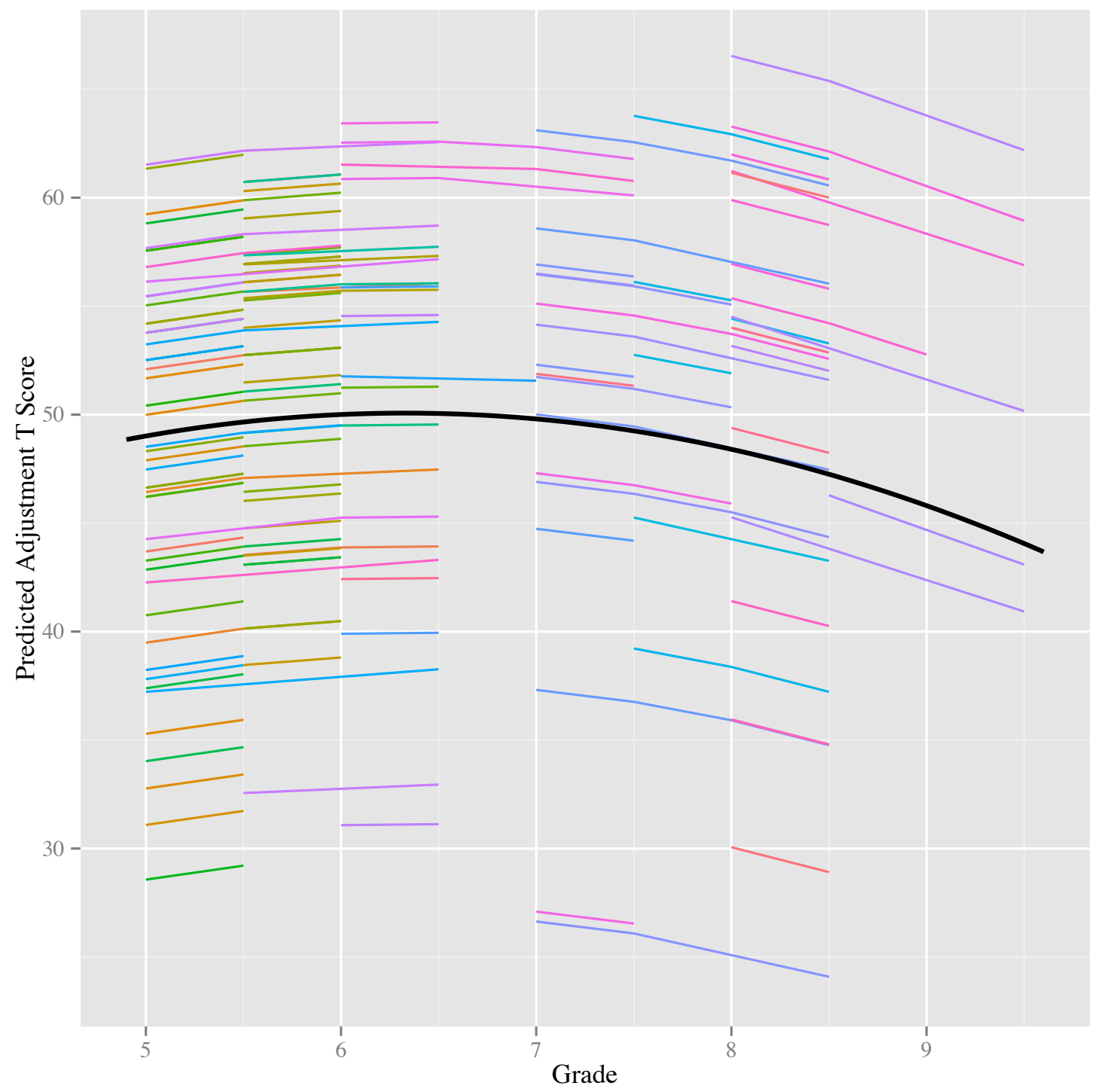

Figure 26. Post-Hoc: Results for predicted changes in students' personal adjustment across grades. The thick line in the center represents the average slope of personal adjustment across grades. The thinner lines show students' predicted personal adjustment when all students have the same slope. 
For risky behavior, there were quadratic effects for students' alcohol use $\left(\beta_{10}=0.08, t=2.15\right)$ and cigarette use $\left(\beta_{10}=0.05, t=2.46\right)$ but not for their fighting or carrying of weapons. Specifically, students' alcohol and cigarette use increased from seventh to ninth grade with a steeper increase from eighth to ninth grade. Figures 27 and 28 display changes in students' alcohol and cigarette use across grade levels. Further, for alcohol use, there were time effects such that students increased their alcohol consumption during the last semester regardless of grade level $\left(\beta_{10}=0.02, t=2.37\right)$. For carrying weapons and fighting, there were not significant changes in students' slope across grade levels. However, there were time effects such that students' carrying of weapons $\left(\beta_{10}=0.02, t=2.75\right)$ and fighting $\left(\beta_{10}=0.02, t=2.27\right)$ increased from Spring 2013 onward regardless of grade level. 


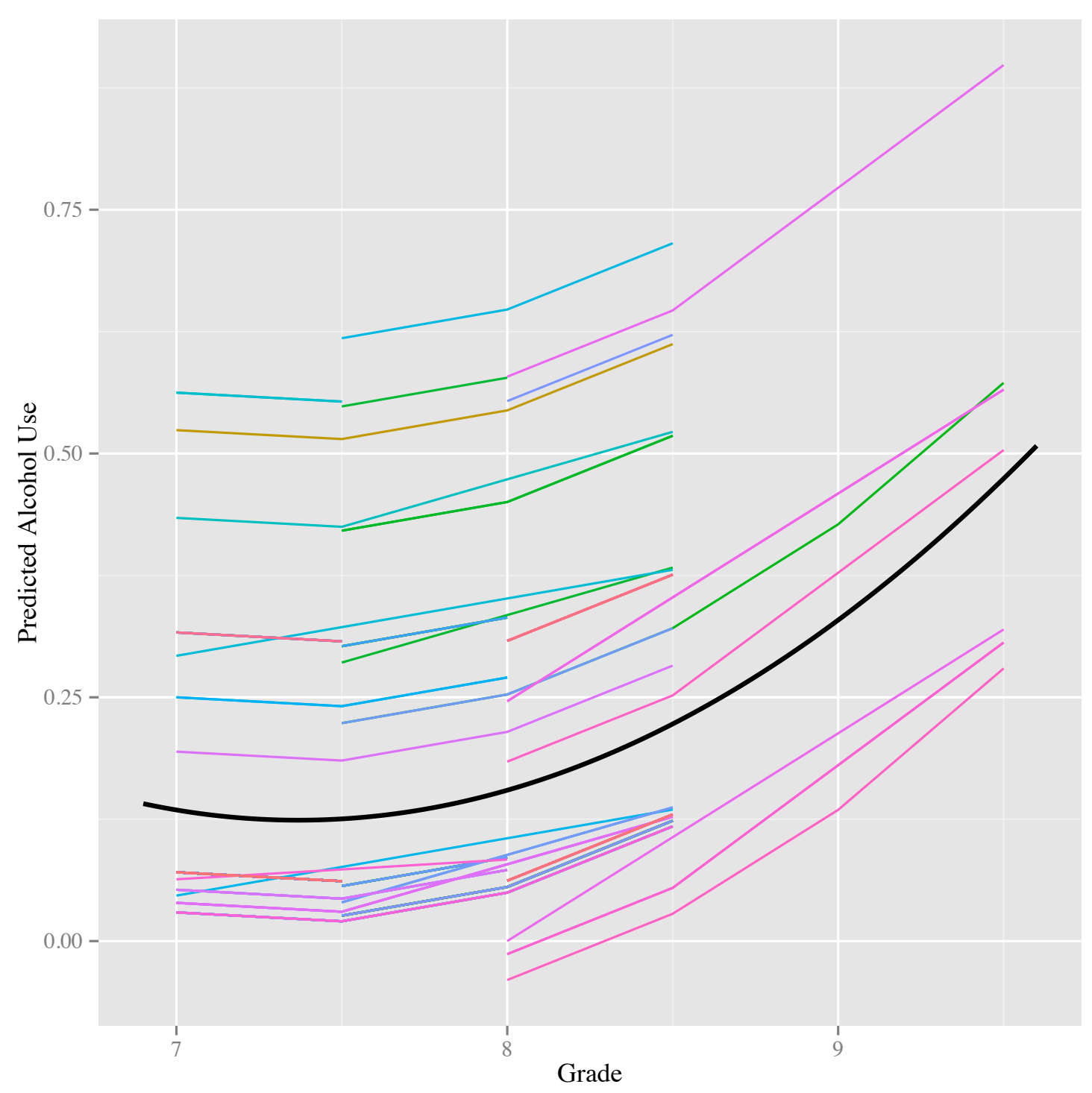

Figure 27. Post-Hoc: Results for predicted changes in students' alcohol use across grades. The thick line in the center represents the average slope of alcohol use across grades. The thinner lines show students' predicted alcohol use when all students have the same slope. 


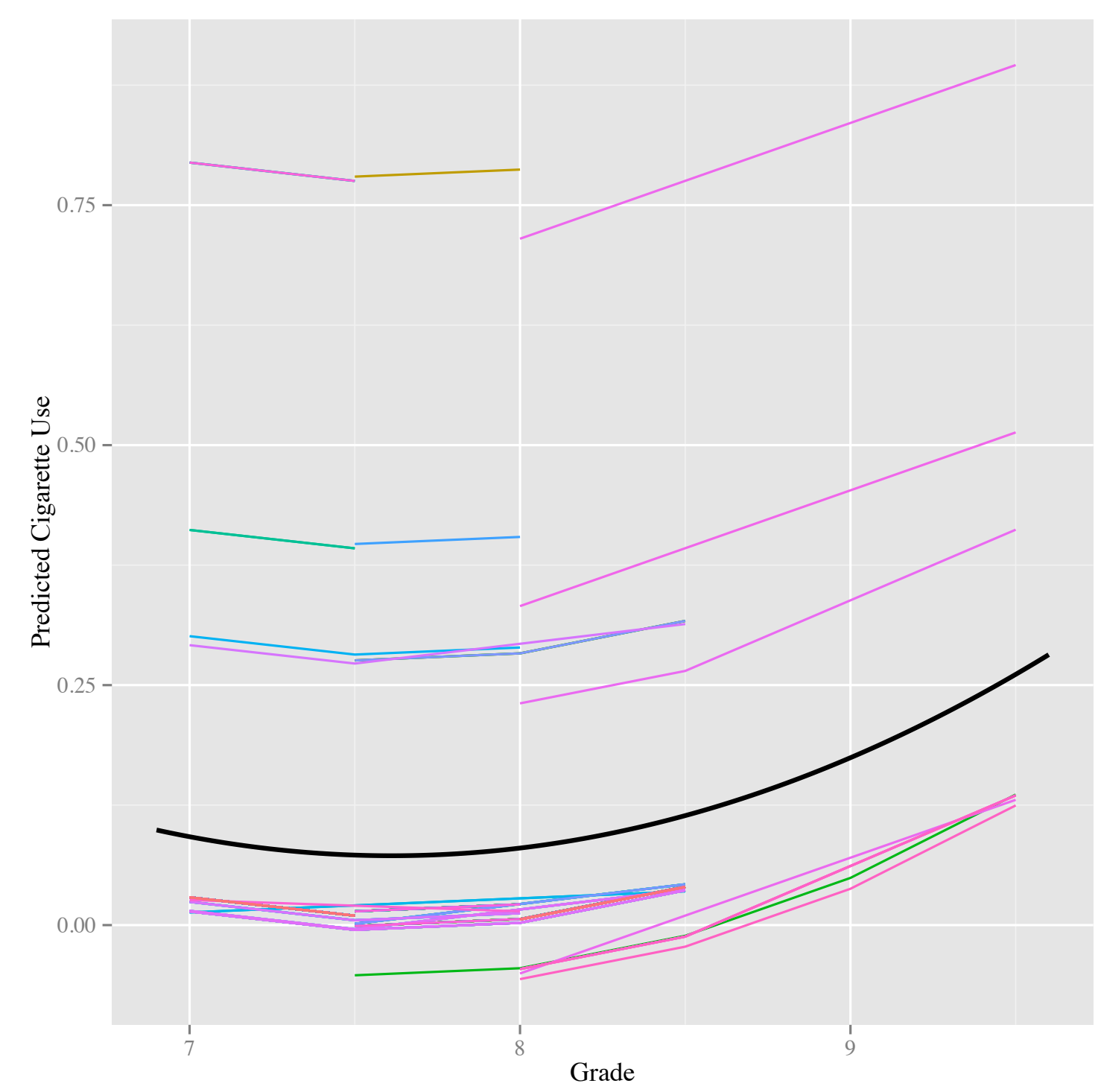

Figure 28. Post-Hoc: Results for predicted changes in students' cigarette use across grades. The thick line in the center represents the average slope of cigarette use across grades. The thinner lines show students' predicted cigarette use when all students have the same slope. 
For academic functioning, students' trajectories depended on the specific academic skill. There were cubic effects for math computation $\left(\beta_{10}=0.32, t=4.96\right)$ and math problem solving $\left(\beta_{10}=0.17, t=2.54\right)$. These findings showed that, relative to same-grade peers on nationally normed tests, students increased their math performance from fifth to sixth grade, maintained their performance in seventh and eighth grade, and increased their performance in ninth grade. There was individual variability in students' math computation trajectories $\left(\beta_{10}=0.58, t=3.01\right)$ and math problem solving trajectories $\left(\beta_{10}=1.19, t=5.75\right)$. Figures 24 and 25 show students' math computation and problem solving performance across grade levels. Further, there were time effects influencing students' math problem solving performance such that students experienced lower performance in Spring 2013 but higher performance during the 2013-2014 school year. For reading, there were cubic effects for reading comprehension $\left(\beta_{10}=0.12, t=\right.$ 2.64) and quadratic effects for reading fluency $\left(\beta_{10}=-0.43, t=-3.36\right)$. For reading comprehension, students' improved their performance relative to same-grade peers from fifth to seventh grade, maintained their performance relative to peers from seventh to ninth grade, and increased their performance relative to peers in ninth grade. For reading fluency, students' performance slightly improved from fifth to seventh grade and then declined after seventh grade relative to peers. Figures 29 through 32 display students' math and reading performance across grade levels. There was time effects such that students had lower reading comprehension performance in Fall 2012 but then improved their performance during later semesters and had higher reading fluency performance during the 2013-2014 school year compared to earlier semesters. 


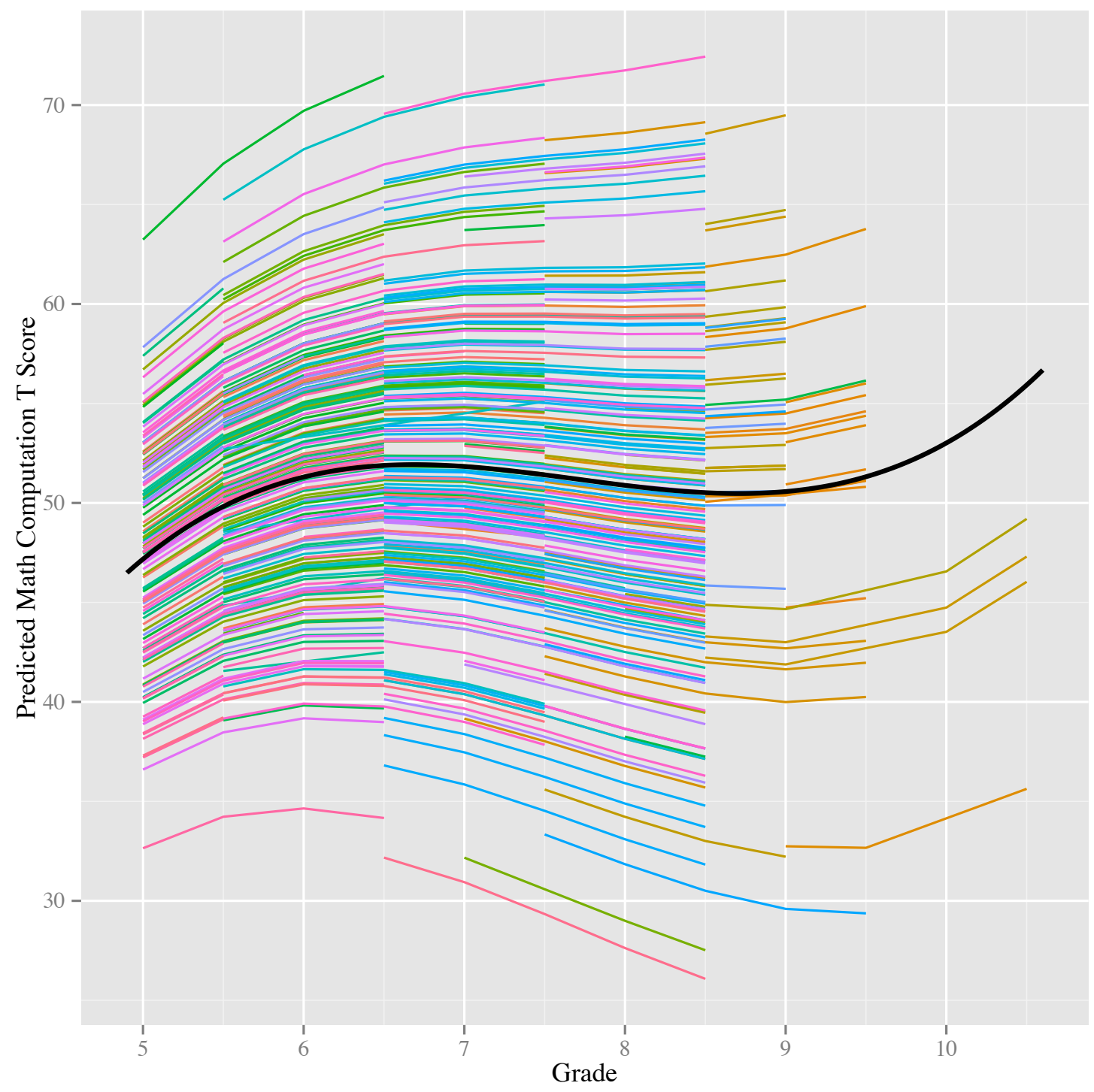

Figure 29. Post-Hoc: Results for predicted changes in students' math computation performance across grades. The thick line in the center represents the average slope of math computation across grades. The thinner lines show students' predicted math computation when all students have the same slope. 


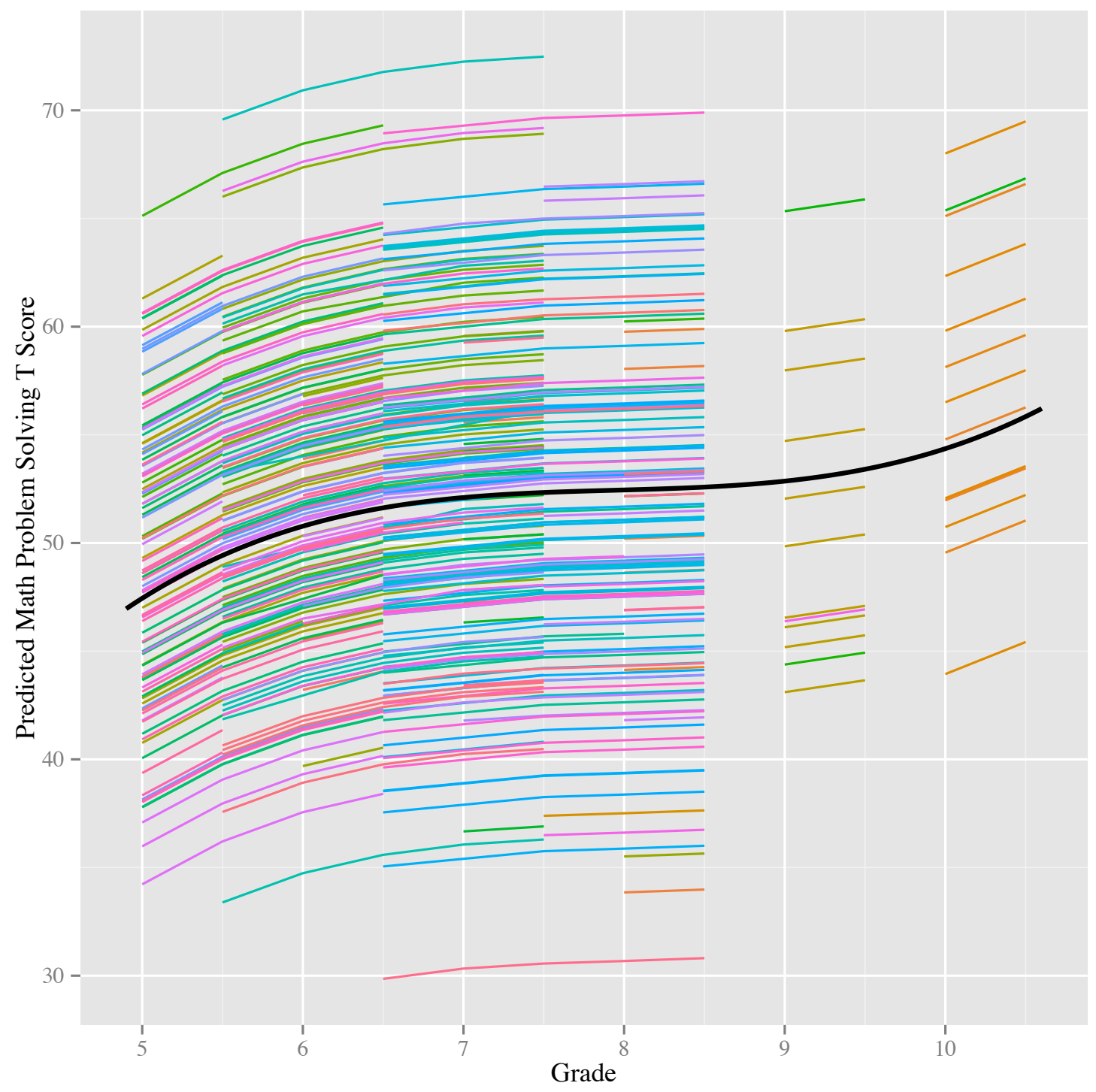

Figure 30. Post-Hoc: Results for predicted changes in students' math problem solving performance across grades. The thick line in the center represents the average slope of math problem solving across grades. The thinner lines show students' predicted math problem solving when all students have the same slope. 


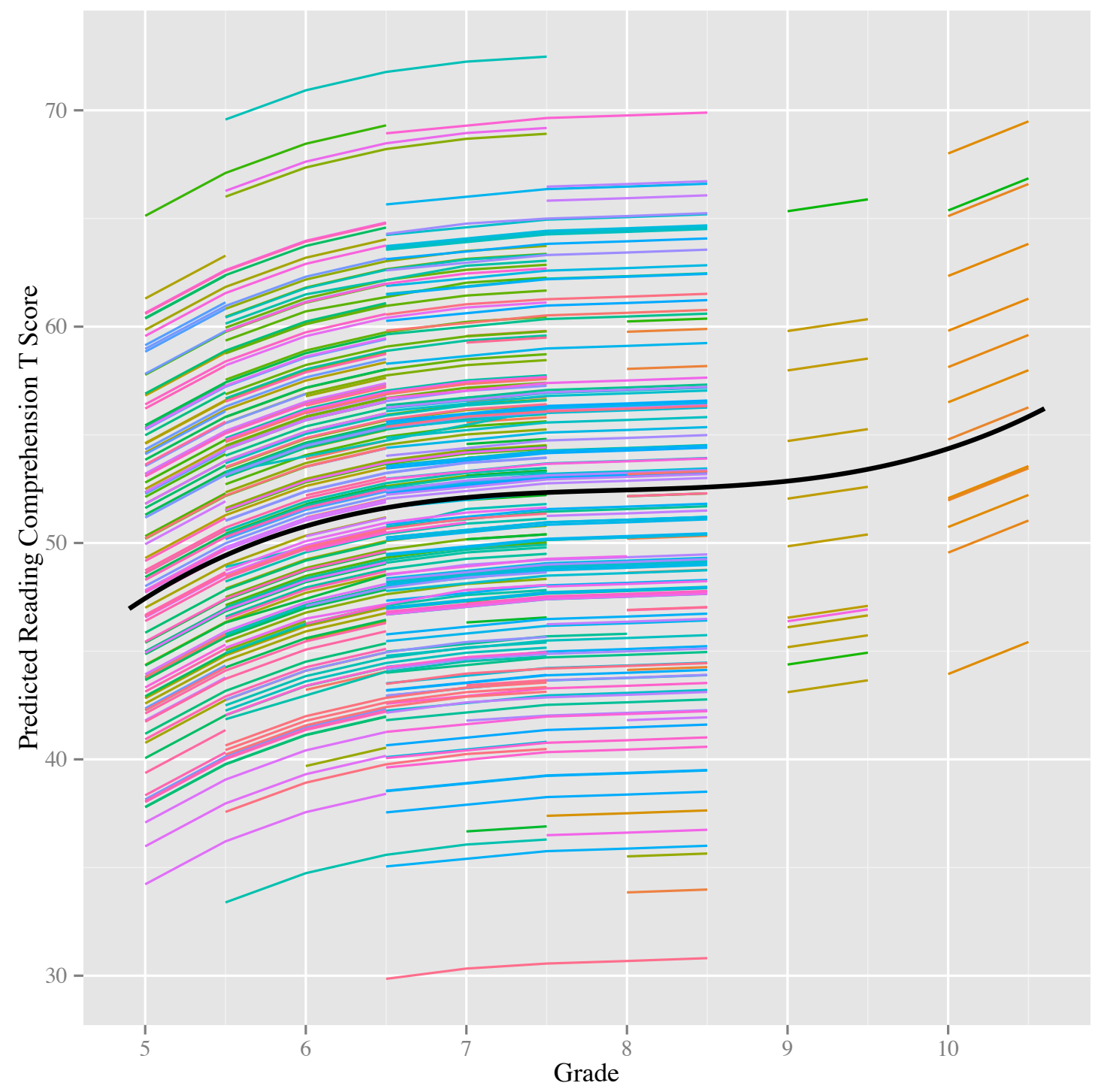

Figure 31. Post-Hoc: Results for predicted changes in students' reading comprehension performance across grades. The thick line in the center represents the average slope of reading comprehension across grades. The thinner lines show students' predicted reading comprehension when all students have the same slope. 


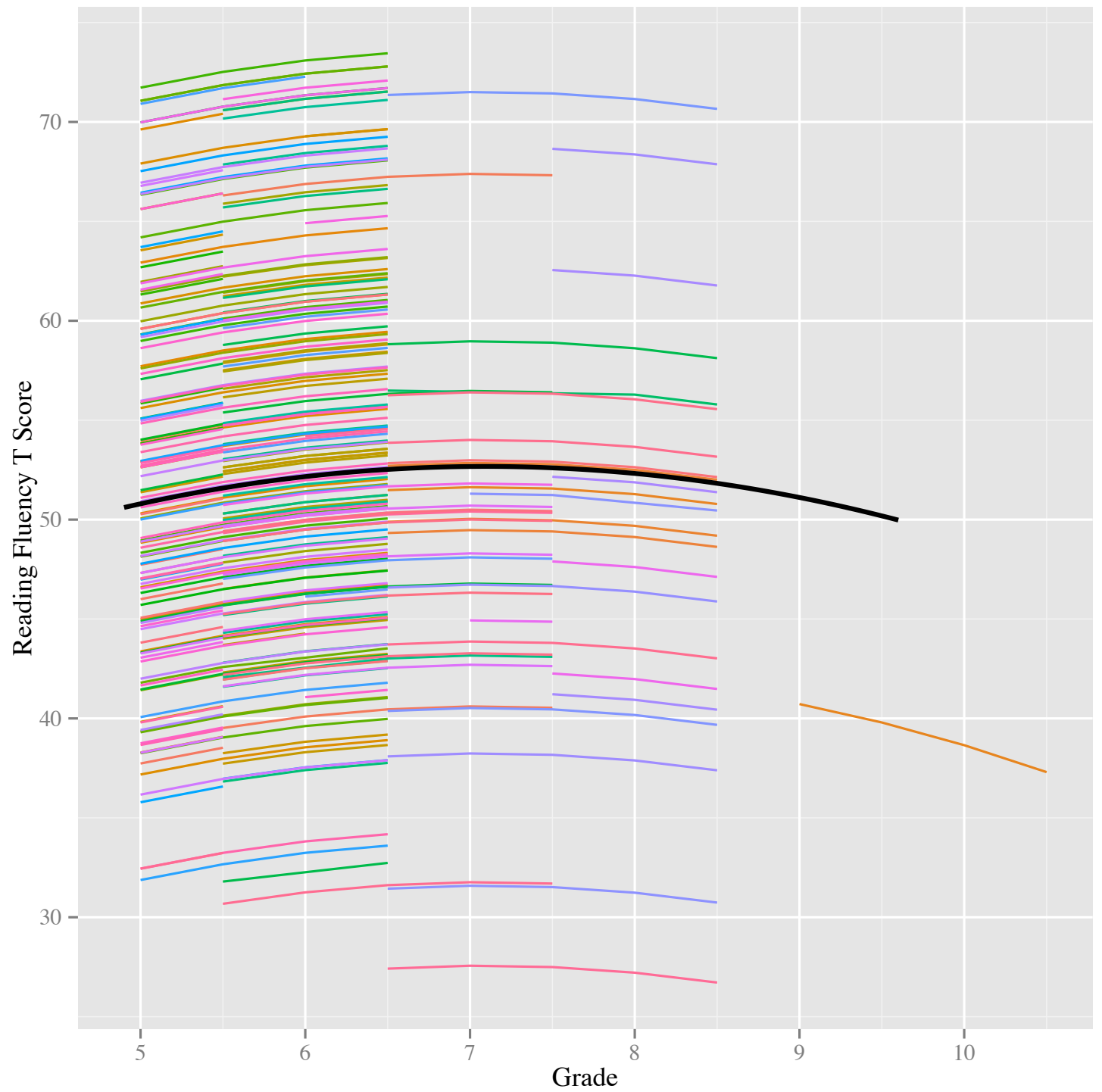

Figure 32. Post-Hoc: Results for predicted changes in students' reading fluency performance across grades. The thick line in the center represents the average slope of reading fluency across grades. The thinner lines show students' predicted reading fluency when all students have the same slope. 


\section{CHAPTER V}

\section{SUMMARY, CONCLUSIONS, AND RECOMMNEDATIONS}

The purpose of the present study was to replicate previous studies and extend the school climate literature as well as to guide educational practices and policies that enhance student outcomes. I investigated the relation between school climate and students' academic, social-emotional, and behavioral functioning over time in rural middle schools. More specifically, I studied the social dimension of school climate using grade-appropriate climate scales from the Developmental Studies Center: Child Development Project (DSC, 2005). These scales measured students' sense of support and their autonomy and influence at school. I also examined the influence of individual differences (i.e., gender and grade level) on school climate perceptions.

Students' academic functioning included their math computation, math problem solving, reading comprehension, and reading fluency performance, which was measured using AIMSweb Curriculum-Based Measures. Students' social-emotional functioning consisted of their internalizing problems and personal adjustment, which was measured using the Behavior Assessment System for Children, Second Edition: Self-Report of Personality (BASC-2: SRP; Reynolds \& Kamphaus, 2004). Students’ risky behavior included fighting, carrying weapons, drinking alcohol, and smoking cigarettes, which was assessed using the Youth Risk Behavior Survey (YRBS) from the Center for Disease Control and Prevention (CDC, 2011). 
To replicate studies and extend previous school climate research, I developed the following hypotheses: (1) students in lower grade levels and girls would have more positive initial climate perceptions than students in higher grade levels and boys (Kuperminc et al., 2001; McGraw et al., 2008) Way et al., 2007); (2) students' climate perceptions would become more negative as they entered higher grade levels (Kuperminc et al., 2001; Way et al., 2007); (3) climate perceptions would be related concurrently to students' academic, social-emotional, and behavioral functioning such that students with more positive perceptions would have higher math and reading scores, better personal adjustment, and fewer internalizing problems and risky behaviors (e.g., Brand et al., 2003; DeWit et al., 2010; Kasen et al., 1990; LaRusso et al., 2008; LaRusso \& Selman, 2011; McGraw et al., 2008; Shirley \& Cornell, 2012; Stewart \& Suldo, 2011; Suldo et al., 2012; Way et al., 2007; Zaykowski \& Gunter, 2011); and, (4) there would be unidirectional effects such that climate perceptions would predict students' future socialemotional, behavioral, and academic functioning but students' previous functioning would not predict their future climate perceptions (Kuperminc et al., 2001; Shochet et al., 2006; Way et al., 2007). I investigated these hypotheses using multiple analysis models, such as Hierarchical Linear Modeling and Pearson product-moment correlations. Across analyses, results provided partial support for hypotheses.

Findings revealed the relation between students' social climate perceptions and grade level over time. Specifically, there were inverse relations between students' climate perceptions and grade level such that increases in grade level were related to students reporting more negative perceptions of the social climate at school. This 
negative trend held between students at the same time and for the same students over time. These findings were consistent with my hypotheses and past research (e.g., Kuperminc et al. 2001; Way et al., 2007). Both boys and girls experienced similar declines in their social climate perceptions. Nonetheless, this decline was small. On average, climate perceptions remained in the positive range over time. Thus, students experienced support as well as autonomy and influence at school from fifth through ninth grade.

Based on previous theory and research, it is possible that the slight negative trend in social climate perceptions resulted from an incongruence between students' developmental needs and the structure and dynamics of the school environment (Way et al., 2007). Research has shown that students' needs for autonomy, belonging, competence, and safety influence their motivation (Schaps, 2002). The stageenvironment fit approach, based on person-environment fit theory, suggests that ongoing changes in students' developmental trajectories and the school environment must align to result in positive outcomes (Eccles, Midgley, Wigfield, Buchanan, Reuman, Flanagan, \& Iver, 1993). From a review of the research, Eccles et al. (1993) found that middle school classrooms had less student autonomy and more teacher control compared to elementary school classrooms even though early-maturing students expressed a greater need for autonomy. Mismatches between students' developmental needs and teachers' behaviors are related to decreases in motivation and school interest (Eccles et al., 1993). For my study, it might have been beneficial to ask students if the school was meeting their 
individual needs to determine if there were mismatches between students' developmental needs and the environment.

Consistent with past research, results of my study demonstrated that social climate perceptions were concurrently related to student outcomes (e.g., Brand et al., 2003;

DeWit et al., 2012; Hoge et al., 1990; Kasen et al., 1990; Kasen et al., 1998; LaRusso et al., 2008; McGraw et al., 2008; Nasir et al., 2011; O'Brennan \& Furlong, 2010; Shirley \& Cornell, 2012; Shochet et al., 2006; Stewart \& Suldo, 2011; Suldo et al., 2012; Thapa, Cohen, Guffey, \& Higgins-D’Alessandro, 2013; Way et al., 2007; Wilkinson-Lee et al., 2009; Zaykowski \& Gunter, 201). Thus, students who felt supported and had a voice at school had better social-emotional, behavioral, and mathematics outcomes.

For social-emotional functioning, my findings revealed that middle school students who experienced more positive social climate perceptions had fewer internalizing problems (e.g., anxiety and depression) and better personal adjustment (e.g., self-esteem, self-reliance, interpersonal relations) while those with more negative perceptions had more social-emotional problems. Thus, students who felt supported and a sense of autonomy at school had better social-emotional outcomes. Consistently, Way et al. (2007) found that students' autonomy and support from teachers and peers were related to lower levels of depression and higher self-esteem. Other researchers have found these types of relations between students' social-emotional functioning and their support at school (e.g., Brand et al., 2003; LaRusso, et al., 2008; McGraw et al., 2008; Steward \& Suldo, 2001; Suldo et al., 2012). Schools have an opportunity to increase 
factors that protect students from having social-emotional problems, such as by promoting positive social climates characterized by support and student involvement.

Consistent with previous research, results of my study showed inverse relations between students' perceived social climate and their risky behavior (i.e., drinking alcohol, smoking cigarettes, carrying weapons, and fighting). Way et al. (2007) found that middle school students' perceived support and autonomy was associated with their problem behavior (e.g., hitting others, breaking school rules). Other researchers have found similar links between students' social climate perceptions and their risky behavior (e.g., Brand et al., 2003; Kasen 1990, LaRusso et al., 2008). Thus, creating a positive school climate can serve as a school-wide strategy to decrease students' involvement in risky behavior. Decreasing risky behavior at a school-wide level is particularly important in rural areas. Adolescents in rural areas might be at a greater risk for not receiving mental health services, such as for substance abuse or externalizing problems, due to the lack of mental health service providers in these areas (Beebe-Frankenberger, 2008). Specifically, about 85 percent of the nation's areas with shortages of mental health professionals were rural (Beebe-Frankenberger, 2008). These concerns suggest the need for schools to implement prevention and intervention programs (e.g., building a positive school climate) to decrease students' involvement in risky behavior.

In terms of academic achievement, my results showed relations between students' social climate perceptions and their math computation performance but not their math problem solving or reading performance. It is possible that the complexity and novelty of the math curriculum in middle school (e.g., algebra) resulted in students' benefiting from 
extra support and opportunities for student autonomy in the classroom compared to other academic areas that have been mastered by most students (e.g., reading), which may explain why social climate was related to students' math computation but not other academic areas. Pajares and Graham (1999) found that sixth grade students' math selfefficacy, value, effort, and performance decreased throughout the school year. Middle school students' math self-efficacy and performance have been linked to teachers' selfefficacy in the classroom (Midgley, Feldlaufer, \& Eccles, 1989). Further, research has shown that teachers' self-efficacy influenced the climate of their classrooms (i.e., academic and social climates; Ashton, Webb, \& Doda, 1983). It is possible that students' academic outcomes were influenced by teachers' self-efficacy and the academic climate of the classroom, which were not assessed in the present study. Previous research has shown stronger relations between the academic climate and students' academic achievement compared to their perceptions of the social climate (Brand et al., 2003). Similarly, Steward and Suldo (2011) found only small correlations between students' perceptions of support from teachers and parents and their academic achievement (i.e., GPA), with no relations between perceived peer support and academic achievement. Taken together, these findings provide a cross-sectional view of the relations between students' social climate perceptions and their social-emotional functioning, risky behavior, and academic performance. Continuous school climate improvement is essential for maintaining positive student outcomes. Despite research showing the effectiveness of school climate improvement on student outcomes, only half of the states have educational policies that address school climate (Piscatelli \& Lee, 2011). Further, 
these policies tend to be embedded within other policies and do not address school climate as a separate issue (Piscatelli \& Lee, 2011). The U.S. Department of Education has taken an active role in promoting school climate improvement across the nation (American Institutes for Research, 2015). The Safe Supportive Schools (S3) and Project Prevent (P2) has provided states and local agencies with over \$50 million to improve school climate and students' safety and engagement (American Institutes for Research, 2015). These types of federal initiatives have enabled more schools to implement school climate improvement efforts (e.g., character education, moral education, mental health initiatives, social-emotional learning) (Thapa et al., 2013). School leaders must monitor and evaluate these efforts to determine the effects on student outcomes and the functioning of schools (NSCC, 2009).

Beyond concurrent relations, a few studies have demonstrated primarily unidirectional relations between climate perceptions and functioning such that past climate perceptions predicted future functioning but past functioning did not predict future climate perceptions (Kuperminc et al., 2001; Shochet et al., 2006; Way et al., 2007). Consistently, I found that most areas of students' functioning did not predict their future climate perceptions. Further, my results showed that students' climate perceptions predicted their involvement in certain risky behaviors (i.e., fighting and smoking cigarettes) and, as expected, these behaviors did not predict students' future climate perceptions. These unidirectional relations showed that students' past functioning did not bias their future views of school climate. Thus, there seems to be more to school climate than individuals' personal characteristics and feelings. These findings support the 
theoretical view that a positive school climate can serve as a protective factor for students while a negative school climate is a risk factor for students.

From seventh to eighth grade, students engaged in more risky behavior (i.e., alcohol and cigarette use) as their climate perceptions became more negative. National data has shown that the average age for first time alcohol use is 13 years old and between 11 to 15 years old for smoking cigarettes (John Hopkins University, 2010; Johnston, O’Malley, Bachman, \& Schulenberg, 2012). Results of my study showed that 16 percent of students had consumed alcohol, 8 percent had smoked cigarettes, 28 percent had carried weapons, and 42 percent had been in a fight. Consistently, the CDC (2013) found that 15 to 35 percent of middle school students had consumed alcohol, 7 to 25 percent had smoked cigarettes, 20 to 50 percent had carried weapons, and 40 to 60 percent had been in a fight with these rates varying by state. Additionally, in my study, more students engaged in risky behavior during certain semesters, which suggested that systems-level factors (e.g., school climate, prevention and intervention strategies, home-school collaboration) might be influencing students' risky behavior. These findings reveal the need for increasing protective factors. School climate improvement might be one protective factor for decreasing middle school students' risky behavior.

In contrast to previous studies, results of my study did not provide evidence for predictive relations between students' climate perceptions and their social-emotional functioning (e.g., Way et al., 2007; Shochet et al., 2006). In my study, students' school climate perceptions declined from fifth to ninth grade and their social-emotional problems increased from seventh to ninth grade. Consistently, research has shown that 
the average age of onset for depression is 13 to 15 years old, 13 years old for social anxiety, and 11 years old for anxiety disorders in general (ADAA, 2015; Corona, McCarty, \& Richardson, 2013; Kessler, Berglund, Demler, Jin, Merikangas, \& Walters, 2005). About 11 percent of adolescents experience a depressive disorder with depression being the most common disability for individuals starting at age 15 (NIMH, 2015). Additionally, about eight percent of adolescents experience anxiety disorders; however, only 18 percent of these adolescents received mental health services (NIMH, 2015). As mentioned, the lack of mental health providers is a risk factor for individuals in rural communities (Beebe-Frankenberger, 2008). In rural areas, about 67 percent of individuals who experience symptoms of mental illness do not receive treatment (BeebeFrankenberger, 2008). Since students in my study resided in rural communities, it is possible that these students were at risk for not receiving mental health treatment if needed. Further, in my study, students experienced more social-emotional problems during the last year of the study compared to earlier years irrespective of grade level. Thus, it is possible these increases were related to a variety of systems-level factors, such as school climate, having a school transition, and the availability of prevention and intervention programs. Taken together, students might be particularly vulnerable for having social-emotional problems during this time of development. Students might need additional protective factors to prevent them from experiencing these problems.

Findings of my study also showed a lack of predictive relations between students' climate perceptions and their academic functioning. Although school climate perceptions became more negative across grade levels, students' academic performance mainly 
improved or was maintained relative to same-grade peers across grade levels.

Additionally, students had better academic functioning during the 2013-2014 school year compared to previous years. These findings showed that students' academic performance might be influenced by factors beyond school climate. For example, Stewart and Suldo (2011) found that parent support had the strongest correlation with internalizing and externalizing problems and academic achievement for middle school students. Further, rural areas are often characterized by strong community support, which can serve as a protective factor for students (Beebe-Frankenberger, 2008). Thus, it is possible that support from parents and the community might have served as protective factors for students in my study, which helped maintain their academic performance. Future research should explore the predictive value of multiple protective factors and risk factors on students' development.

Across findings, my data seemed to capture relations between climate perceptions and functioning in the moment but less so over time. The lack of predictive relations showed the need for regularly monitoring of school climate and students' functioning. These findings also suggested that students' developmental trajectories are complex and influenced by many internal and external factors at any given time. To elaborate, the middle school years are a particularly notable time for experiencing developmental changes (e.g., biological, cognitive, emotional, and social) (Santrock, 2008). Bronfenbrenner and Ceci (1994) described a bioecological model to understand interactions (i.e., proximal processes) that occur between individuals' personal characteristics and their environmental contexts (e.g., family, peer group, school, 
community). Developmental trajectories are shaped by many biological, psychological, and social-ecological factors, which can combine to influence outcomes (Cicchetti \& Rogosch, 2002; Kazdin et al., 1997). Even more complicated, different levels of the environment interact and influence developmental trajectories (Bronfenbrenner, 1977). Specifically, children and adolescents are influenced directly by their immediate environments, such as their families, peer groups, and schools (i.e., the microsystem) (Bronfenbrenner, 1977). For instance, McGraw et al. (2008) found that adolescents' connectedness to school, family, and peers was related to their internalizing functioning. At the next level, environments interact to influence individuals indirectly, such as interactions between parents and teachers or interactions between the peer group and school (i.e., the mesosystem) (Bronfenbrenner, 1977). For example, Suldo et al. (2012) found that home-school communication and parental involvement in school was associated with students' internalizing and externalizing problems and life satisfaction. Further, environments that do not contain the individual have the potential to influence development indirectly, such as the state board of education (i.e., the exosystem), (Bronfenbrenner, 1977). Lastly, society and culture indirectly shape individuals' development, such as with educational policies on school climate (i.e., the macrosystem), (Bronfenbrenner, 1977).

Students must be viewed as developing within these different ecological levels. Thus, changes within each of the ecological levels have the potential to promote or hinder development. There is a need for longitudinal research to examine interactions between risk and protective factors within these ecological levels to better understand factors that 
influence developmental trajectories. This type of research is critical for informing assessment, prevention, and intervention efforts (Kazdin et al., 1997). My longitudinal study focused on the influence of one aspect of students' microsystem (i.e., school climate) on their development; however, examining the combination of multiple risk and protective factors within the microsystem and other ecological levels might have allowed for the prediction of students' future functioning.

Another reason that climate perceptions did not predict students' social-emotional and academic functioning might have been due to most ratings and test scores being in the average range. Having more variability in school climate perceptions over time might have resulted in students' perceptions predicting their future functioning. For example, Way et al. (2007) found that decreases in school climate perceptions predicted declines in student functioning (depression, behavior problems and low self-esteem) while increases in climate perceptions predicted improved functioning over time. In my study, the average level of school climate decreased slightly from 3.49 to 3.22 on a 5 -point scale with there being little individual variability in these ratings over time. Further, most students were in the average range across areas of functioning, such as internalizing problems $(M=50.47, S D=12.07)$, personal adjustment $(M=49.74, S D=11.30)$, math computation $(M=50.79, S D=9.08)$, math problem solving $(M=51.79, S D=9.61)$, reading comprehension $(M=53.66, S D=8.73)$, and oral reading fluency $(M=51.99, S D$ $=10.10)$. These measures have a mean of 50 and standard deviation of 10 , which was consistent with my findings. It is possible that school climate perceptions would have been a more powerful predictor for students who were more at-risk for adverse outcomes 
(Bronfenbrenner \& Ceci, 1994). For instance, Kuperminc et al. (2001) found that students with more psychological vulnerability (i.e., high self-criticism and low selfefficacy) were protected from increases in internalizing and externalizing problems when they had positive climate perceptions. This research demonstrated that school climate served as a protective factor for at-risk students.

It is possible that obtaining a larger sample of students from each school might have resulted in the inclusion of more at-risk students that would have led in turn to stronger findings. It is plausible that the specific recruitment strategies for this study (i.e., sending home parent consent forms and attending school registration sessions) might have contributed to the recruitment of a higher functioning sample of students. For instance, students who were less involved in school might not have given the consent forms to their parents. Some parents might not have been available to attend the school registration session. At the registration sessions, some parents might have been overwhelmed by all of the school information or had little time, so they did not speak to the researchers about the study. Modifications to recruitment efforts might address these issues and increase the heterogeneity of the sample. For example, researchers could call parents to explain the study, talk to students about the study at school, mail consent forms to parents, and attend multiple school events to obtain parental consent (e.g., school open houses or parent-teacher conferences).

Similarly, another explanation for the lack of predictive power in my study was the requirement of having active parental consent for student participation, which resulted in the assessment of climate perceptions from only a portion of students at each school. 
One solution to this issue is measuring students' climate perceptions at a school-wide level regularly. In recent years, more states have begun to address school climate assessment and improvement in their educational policies (Cohen, 2014). Ideally, schools should partner with researchers to collect school-wide climate data over time.

Developmental trajectories are probabilistic in that risk and protective factors influence the continuity and discontinuity of adaptive or maladaptive functioning at each point in time (Cicchetti \& Rogosch, 2002). Having a positive school climate might allow individuals to continue functioning at adaptive levels (e.g., average range), such as in my study, or might improve the functioning of at-risk individuals, such as in they study by Kuperminc et al. (2001). Additionally, the effect of school climate on functioning might depend on its relation and interaction with other factors (Kazdin et al., 1997). Resilience research is critical for identifying protective factors that are internal and external to the individual. To better understand resilience, Masten (2007) recommended investigating relations between personal and ecological factors (e.g., attachment, problem-solving skills, self-regulation, self-efficacy, motivation, spiritual and religious beliefs, family systems, peer relations, school climate, community factors, and cultural factors). My study focused on one area within resilience research (i.e., school climate); however, including additional areas might have revealed additive or interactive effects between these protective factors on students' development.

The lack of predictive relations in my study might have also resulted from focusing on the social dimension of school climate as opposed to using a more comprehensive definition that included the academic and physical dimensions. Future 
studies should use the National School Climate Council's (2013) definition of school climate (i.e., safety, relationships, teaching and learning, institutional environment, and the school improvement process) (Thapa et al., 2013). Research has demonstrated relations between these dimensions and student outcomes in cross-sectional studies (e.g., Brand et al., 2003; CEP, 2013; Crosnoe et al., 2002; Loukas, 2007; NSCC, 2012; Steward and Suldo, 2011). Future research should longitudinally explore the incremental validity of predicting student outcomes by adding additional dimensions of school climate.

Another way to measure school climate more holistically would be to use a multiinformant approach. The National School Climate Council (NSCC, 2009) created standards to improve the climate of schools. One of the five main standards addressed the importance of including a variety of informants to evaluate school climate (NSCC, 2009). Specifically, the NSCC (2009) asserted that schools should "gather accurate and reliable data about school climate from students, school personnel and parents/guardians for continuous improvement and share it regularly with the school community" (p. 4). Schools must examine school climate data from multiple informants to develop policies that enhance school climate (Kim, Schwartz, Capella, \& Seidman, 2014; NSCC, 2009; Thapa et al., 2013). This type of multi-informant school climate assessment might provide additional power in predicting student outcomes.

Additionally, a multi-method approach that assesses both the subjective and objective nature of school climate might add predictive value. In my study and most research studies, school climate has been assessed using subjective ratings. However, there is a lack of research exploring both subjective and objective dimensions of school 
climate on student outcomes. Kuperminc et al. (2001) stated that the objective school climate might influence subjective perceptions. Way et al. (2007) mentioned that research should explore discrepancies between the subjective and objective school climate. Objective indicators of school climate might include the presence of a shared school mission statement and goals, students' attendance and discipline records, the presence of school-wide policies and practices (e.g., Positive Behavioral Interventions and Supports, social-emotional learning curricula), the number of academic and elective offerings, the number of clubs and extracurricular activities with the percentage of student participation, the number of opportunities for parent involvement with the percentage of parent participation, the number of professional development trainings, school and classroom size, financial expenditure per students, and other numeric variables. Future research should explore relations between the subjective and objective dimensions of school climate and the predictive value of these dimensions on students' development.

School climate should also be examined at individual and group levels. My study used individual-level analyses due to the small sample size of schools, which prevented analyses on school-level climate using Hierarchical Linear Modeling (HLM). Students are nested within different groups (e.g., classrooms, teaching teams, grades, schools). Examining nested data is important due to individuals from the same context often being more similar than they are to individuals from different contexts; additionally, individuallevel analyses do not reveal the influence of group-level factors (Kahn, 2011). Kahn (2011) stated, "Individual-level analyses cannot adequately capture the role of group- 
level factors" (p. 258). For example, research has shown that school-level variables (e.g., school size, finances, race/ethnicity composition, student mobility, faculty turnover) influence students' functioning (Gregory et al., 2011; Koth et al., 2008). Brand et al. (2003) recommended examining variability in climate perceptions between schools and between subgroups within a school (e.g., race/ethnicity, gender, grade, socioeconomic status). Several researchers have recommended the use of HLM to examine both within school and between school variability in climate perceptions (e.g., Brand et al., 2003; Koth et al., 2008; Suldo et al., 2012). Brand et al. (2003) stated that "school-level scores on the climate scales account for a meaningful amount of variation in students' adjustment outcomes and that the data provided by these ratings can inform our efforts to carry out comprehensive school improvement” (p. 584).

School climate data should be used to identify students who are at-risk for negative outcomes due to the link between students' climate perceptions and functioning. School climate assessment and improvement should be part of schools' Multi-Tiered System of Supports (MTSS), which was formerly titled Response-to-Intervention (RtI). MTSS/RtI is defined as a "systems-based and preventive educational model that incorporates scientifically based measurement and instructional practices with systematic data collection, analysis, and decision making to meet the educational needs of all students in a school setting" (Cates, Blum, \& Swerdlik, 2011, p.1). Using an MTSS/RtI approach can enhance school climate and student functioning (Osher, Sprague, Weissberg, Axelrod, Keenan, Kendziora, \& Zins, 2008). Within this model, school climate improvement is a universal strategy (Tier I) to improve student outcomes and 
school contexts (Cowan, Vaillancourt, Rossen, \& Pollitt, 2013). At the universal level, data on students' academic, social-emotional, and behavioral performance should be assessed three times per year (Cates et al., 2011). Data collection on school climate should be incorporated into schools' universal assessment procedures. These data could be used to identify students who are at-risk for negative outcomes and provide them with more intensive interventions (Tier II or Tier III) as well as to identify contexts in need of improvement. Kuperminc et al. (2001) emphasized that schools should implement person-centered skill-building interventions and make environmental modifications (e.g., school climate improvement) to enhance student outcomes. Schools should use a developmental-ecological approach to implement interventions and create environments that align with students' needs.

At a universal (Tier I) level, the following are evidence-based strategies to improve students' belonging and autonomy: (1) students, families, school staff, and community members should form collaborative partnerships to make educational decisions (e.g., creating school missions, goals, and policies); (2) schools should communicate regularly to parents, provide family support programs and trainings, and encourage parents to volunteer in school events; (3) schools should use strategies that increase students' active engagement (e.g., establishing high academic standards for all students, providing personalized learning, implementing curriculum relevant to students' lives, and using flexible instructional practices to meet students' needs); and, (4) schools should support staff members (e.g., providing professional development and creating teaching teams) to better meet students' needs (Blum, 2004; CDC, 2009). Additionally, 
Blum (2004) recommended that schools should ensure that "every student feels close to at least one supportive adult at school" (p. 2). Every student should have an assigned school staff member who watches out for the student and checks in with him or her periodically (Blum, 2004). For instance, advisory programs can help students feel connected and supported in schools (Center for Social and Emotional Education, 2015). Implementing a school-wide buddies program in which older students mentor younger students can also increase students' school connectedness (Schaps, 2002).

Also, at a Tier I level, teachers can create classrooms that increase students' sense of belonging and autonomy. Teachers should use effective classroom management and instructional practices to create positive classroom environments (e.g., including collaborative learning experiences, using interactive and experiential learning, having peer-assisted tutoring, rewarding positive behavior, creating a democratic classroom, assigning classroom jobs and roles to students, and sharing positive news to parents regularly) (Blum, 2004; Catalano, Haggerty, Oesterle, Fleming, \& Hawkins, 2004; CDC, 2009). Research from the Child Development Project (CDP) showed that students' belonging and autonomy increased when teachers incorporated cooperative learning activities and held class meetings, which allowed for collaborative goal-setting, planning, decision-making, and problem-solving (Schaps, 2002). Studies have shown that children and adolescents differentiate between autonomy enhancing instruction (i.e., providing choice, allowing criticism, and fostering relevance) and autonomy suppressing instruction (i.e., criticism, intruding, and forcing meaningful acts) with the former being linked to more positive outcomes (Assor, Kaplan, \& Roth, 2002). Giving students' a voice to 
make decisions in school enable them to experience autonomy, belonging, and competence (Mitra, 2004). A developmental-ecological perspective should be used to create a climate aligned with students' developmental needs (e.g., support and autonomy).

As schools implement these evidence-based strategies at school and classroom levels, climate assessments should be used regularly to monitor changes in students' school climate perceptions. Results of my study revealed the need for continual assessment and improvement of school climate. Schools should implement curriculum and instructional practices aligned with students' developmental needs. Students in middle school might need additional protective factors to prevent them from experiencing social-emotional, behavioral, and academic problems. Creating a positive school climate has the potential to improve students' functioning, particularly in rural areas.

Despite these valuable findings, there were limitations of my study, which should be addressed by future research. First, I examined the effects of the social dimension of school climate (i.e., perceived support and autonomy/influence) on student outcomes. Future research should define school climate more comprehensively, such as by using the NSCC's (2013) definition that included safety, relationships, teaching and learning, institutional environment, and the school improvement process (Thapa et al., 2013). Having a comprehensive definition of school climate might reveal stronger relations between climate perceptions and students' academic, behavioral, and social-emotional outcomes (e.g., Brand et al., 2003). Future research should explore the direction of 
effects of these school climate dimensions on students' overall development and learning as well as on outcomes for families and school staff.

Next, I assessed the social climate from the perspective of students only; however, future researchers should use a multi-informant approach by measuring the climate perceptions of students, school staff, families, and community members (Thapa et al., 2013). Similarly, in the present study, I used self-reports only to assess students' socialemotional and behavioral outcomes; however, future researchers should collect data using a multi-informant and multi-method approach (e.g., parent and teacher ratings, attendance and discipline records, intervention history). Additionally, future studies should use a multi-method approach by examining both subjective and objective aspects of school climate

The level of analysis was also a limitation of the study. In particular, I focused on examining climate perceptions at the individual level as opposed to the school level due to the sample size of schools being to small to use Hierarchical Linear Modeling (HLM) for analyses at the school level. Future research should explore the relation between climate and student outcomes at multiple levels (e.g., individual, classroom, teaching team, grade, school).

As mentioned, another limitation of my study was the specific strategies for recruitment and the requirement of active parental consent to collect student data. It is possible that participating students differed in some way from students who were not in the study. For instance, families and students who agreed to participate in the study might feel more connected and involved in the school than those who did not participate. 
These families and students might also be more motivated to contribute to school decision-making than those who declined participation in the study. Additionally, some students dropped out of the study or refused to complete measures during survey sessions. These students might have been less agreeable and cooperative, more negative about school, more easily influenced by negative peer pressure, or more likely to engage in oppositional behavior than peers who stayed in the study and completed measures. Obtaining data from all students in the school would have provided a more accurate representation of students' views on school climate. Ideally, schools should include school climate assessment as a routine, school-wide practice that does not require active parental consent. This school-wide climate data would enable school staff and researchers to more accurately assess school climate and the effectiveness of climate improvement efforts. Brand et al. (2003) emphasized the importance of collecting climate data that represent school-wide views and examining the perceptions of subpopulations within the student body to identify within-school variability of perceived climate to guide improvement strategies. Additionally, the current study examined changes over time in students' climate perceptions and functioning but did not include an intervention component to improve school climate. Thus, future studies should examine the effects of school climate improvement strategies on outcomes over time (CDC, 2009). Lastly, I did not examine the influence of students' individual differences, beyond gender and grade level, on students' school climate perceptions and functioning in my study. As described in Chapter III, missing demographic information and a largely homogeneous sample made it impossible to examine the effects of traditional 
demographic categories in this study. Future researchers should explore the influence of these characteristics (e.g., disability status, socioeconomic status, and race/ethnicity) on students' climate perceptions and functioning. Further, my study examined school climate as a protective factor but not other potentially influential factors (e.g., teachers' self-efficacy, family connectedness, community involvement). Future researchers should explore the potential additive or interactive effects of various protective factors on student outcomes from a developmental-ecological perspective.

Taken together, future researchers should define school climate comprehensively using a multi-method (i.e., objective and subjective indicators) and multi-informant approach. Researchers should partner with schools to collect school-wide climate data that are representative of the entire student body. Future research should further investigate the direction of effects using longitudinal studies of school climate on outcomes for students, school staff, and families.

Although there were limitations, the present study had several strengths. First, I used a longitudinal design that allowed for assessment of a large group of students over time. The study replicated previous research and expanded the literature by including multiple outcomes (i.e., academic, social-emotional, and behavioral functioning) within this longitudinal study. I examined the direction of relations between students' climate perceptions and functioning, which has been less studied by previous researchers. As part of the middle school sample, I included fifth grade students while previous studies have mainly focused on sixth through eighth grade students. Next, I used empiricallysupported assessment tools, such as climate scales from the Developmental Studies 
Center: Child Development Project (DSC, 2005), AIMSweb Curriculum-Based

Measures, the Behavior Assessment System for Children, Second Edition: Self-Report of Personality (BASC-2: SRP; Reynolds \& Kamphaus, 2004), and the Youth Risk Behavior Survey (YRBS) from the Center for Disease Control and Prevention (CDC, 2011).

Lastly, I examined the functioning of students and schools in rural areas, which has often been overlooked in the literature.

Overall, the present study showed that school climate is one piece of a complex, puzzle for understanding the developmental trajectories of middle school students. School climate is best characterized as a universal (Tier I) prevention strategy for improving students' functioning. School climate assessment provides a snapshot of the functioning of students and school systems at any given time. These data can be used to identify students who are at-risk for negative academic, social-emotional/mental health, and behavioral outcomes. School climate data can also be used to continually improve school contexts and practices. Middle school students' developmental trajectories are influenced by numerous protective and risk factors. Continued research is needed on the interaction and influence of personal characteristics and ecological contexts (e.g., school climate) on students' development.

In closing, schools have the opportunity to provide protective factors to students. Some students experience low academic performance, pressure to engage in risky behavior, and mental health disorders. Nonetheless, schools can create a positive climate to decrease the likelihood that students will experience these concerns. Research has consistently demonstrated that students who feel safe, supported, involved, and respected 
in school have better social-emotional/mental health, behavioral, and academic outcomes.

Schools should incorporate evidence-based climate assessment and improvement strategies into their policies and practices to enhance student outcomes. School climate has the potential to positively influence students' learning and development. 


\section{REFERENCES}

American Institutes for Research. (2015). Safe supportive learning: State/grantee profiles. Retrieved from http://safesupportivelearning.ed.gov/stategrantee-profile.

Anderson, C. S. (1982). The search for school climate: A review of the research. Review of Educational Research, 52(3), 368-420. doi:10.3102/00346543052003368

Anxiety and Depression Association of America. (2015). Social anxiety disorder. Retrieved from http://www.adaa.org/understanding-anxiety/social-anxietydisorder.

Ashton, P. Webb, R., \& Doda, C. (1983). A study of teachers' sense of efficacy (Final report, Executive Summary). Gainesville: University of Florida.

Assor, A., Kaplan, H., \& Roth, G. (2002). Choice is good, but relevance is excellent: autonomy-enhancing and suppressing teacher behaviours predicting students' engagement in schoolwork. British Journal of Educational Psychology, 72(2), 261-278. doi:10.1348/000709902158883

Bates, D. (2005). Fitting linear mixed models in R. $R$ News, 5(1), 27-30.

Beebe-Frankenberger, M. (2008). Best practices in providing school psychological services in rural settings. In Thomas, A. \& Grimes, J. (Eds.), Best practices in school psychology (pp. 1785-1807). Bethesda, MD: NASP Publications.

Benard, B. (1991). Fostering resiliency in kids: Protective factors in the family, school, and community. Western Regional Center for Drug-Free Schools and Communities, 1-27.

Blum, R. (2004). School connectedness: improving students' lives. John Hopkins Bloomberg School of Public Health. Baltimore, MD. Retrieved from http://cecp.air.org/download/MCMonographFINAL.pdf.

Brand, S., Felner, R., Shim, M., Seitsinger, A., \& Dumas, T. (2003). Middle school improvement and reform: development and validation of a school-level assessment of climate, cultural pluralism, and school safety. Journal of Educational Psychology, 95(3), 570-588. doi:10.1037/0022-0663.95.3.570 
Bronfenbrenner U. (1977). Toward an experimental ecology of human development. American Psychologist, 513-531. doi:10.1037/0003-066X.32.7.513

Bronfenbrenner U. \& Ceci, S. J. (1994). Nature-nurture reconceptualized in developmental perspective: A bioecological model. Psychological Review, 101(4), 568-586. doi:10.1037/0033-295X.101.4.568

Catalano, R. F., Haggerty, K. P., Oesterle, S., Fleming, C. B., \& Hawkins, J. D. (2004). The importance of bonding to school for healthy development: findings from the social development research group. Journal of School Health, 74(7), 252-261.

Cates, G. L., Blum, C., \& Swerdlik, M. E. (2011). Effective RtI training and practices: Helping school and district teams improve academic performance and social behavior. Champaign, IL: Research Press.

Center for Disease Control and Prevention. (2009). School connectedness: strategies for increasing protective factors among youth. Atlanta, GA: U.S. Department of Health and Human Services.

Center for Disease Control and Prevention. (2011). School connectedness: strategies for increasing protective factors among youth. Atlanta, GA: U.S. Department of Health and Human Services. Retrieved from http://www.cdc.gov/HealthyYouth/health_and_academics/.

Center for Disease Control and Prevention. (2011). Middle school youth risk behavior survey. Atlanta, GA: U.S. Department of Health and Human Services. Retrieved from http://www.cdc.gov/healthyyouth/yrbs/pdf/questionnaire/2011_ms_questionnaire. pdf.

Center for Disease Control and Prevention. (2013). Youth online: high school YRBS. Retrieved from https://nccd.cdc.gov/youthonline/App/Default.aspx.

Center for Social and Emotional Education. (2009). School climate guide for district policymakers and education leaders. Retrieved from http://ceep.indiana.edu/hssse/pdfs/district-guide-csee.pdf.

Center for Social and Emotional Education. (2015). Reaching every child: developing a middle school advisory program. Retrieved from http://www.schoolclimate.org/programs/documents/workshop04AReachingEveryChild.pdf.

Character Education Partnership. (2013). School climate. Retrieved from http://www.character.org/key-topics/school-climate/. 
Cicchetti, D. \& Rogosch, F. A. (2002). A developmental psychopathology perspective on adolescence. Journal of Consulting and Clinical Psychology, 70, 6-20. doi:10.1037//0022-006X.70.1.6

Clopton, K. L. \& Knesting, K. (2006). Rural school psychology: Re-opening the discussion. Journal of Research in Rural Education, 21(5), 1-11. Retrieved from http://jrre.psu.edu/articles /21-5.pdf.

Cohen, B. \& Thomas, E. B. (1984). The disciplinary climate of schools. The Journal of Educational Administration, 22(2), 113-135. doi:10.1108/eb009888

Cohen, J. (2006). Social, emotional, ethical, and academic education: Creating a climate for learning, participation in democracy, and well-being. Harvard Educational Review, 76, 201-237. doi:10.17763/haer.76.2.j44854x1524644vn

Cohen, J., Pickeral, T., \& McCloskey, M. (2009). Assessing school climate. The Educational Digest, 45-48.

Cohen, J., McCabe, E. M., Michelli, N. M., \& Pickeral, T (2009). School climate: research, policy, practice, and teacher education. Teachers College Record, 111, 180-213.

Cohen, J. (2014). School climate policy and practice trends: A paradox. Retrieved from http://www.schoolclimate.org/publications/documents/SCPolicy\&PracticeTrendsCommentaryTCRecord2-28-14.pdf.

Collins, T. N. \& Parsons, K. A. (2010). School climate and student outcomes. Journal of Cross-Disciplinary Perspectives in Education, 3, 34-39.

Cook, C. R., Williams, K. R., Guerra, N. G., Kim, T. E., \& Sadek, S. (2010). Predictors of bullying and victimization in childhood and adolescence: A meta-analytic investigation. School Psychology Quarterly, 25, 65-83. doi:10.1037/a0020149

Corona, M., McCarty, C. A., \& Richardson, L. P. (2013). Screening adolescents for depression. Contemporary Pediatrics. Retrieved from http://contemporarypediatrics.modernmedicine.com/contemporarypediatrics/content/tags/depression/screening-adolescents-depression?page=full.

Corrigan, M. W., Klein, T. J., \& Isaacs, T. (2010). Documenting the relationship of students' trust in teachers to cognition, character, and climate. Journal of Research in Character Education, 8, 61-73. 
Cowan, K. C., Vaillancourt, K., Rossen, E., \& Pollitt, K. (2013). A framework for safe and successful schools. Bethesda, MD: National Association of School Psychologists.

Crosnoe, R., Erickson, K. G., \& Dornbusch, S. M. (2002). Protective functions of family relationships and school factors on the deviant behaviors of adolescent boys and girls: reducing the impact of risky friendships. Youth \& Society, 33, 515-544. doi:10.1177/0044118X02033004002

Developmental Studies Center (2005). Scales from student questionnaire, child development project middle school student follow-up study (grades 6-8). Oakland, CA. Retrieved from http://www.devstu.org/sites/default/files/media/pdfs/cdp/DSC_MidSch_scales.pdf

Developmental Studies Center (2005). Scales from student questionnaire, child development project for elementary school students (grades 3-6). Oakland, CA. Retrieved from http://www.devstu.org/sites/default/files/media/pdfs/cdp/DSC_ElemSch_scales.p df.

DeWit, D. J., Karioja, K., \& Rye, B. J. (2012). Student perceptions of diminished teacher and classmate support following the transition to high school: are they related to declining attendance? School Effectiveness and School Improvement, 21, 451-472. doi:10.1080/09243453.2010.532010

Eccles, J. S., Midgley, C., Wigfield, A., Buchanan, C. M., Reuman, D., Flanagan, C., \& Iver, D. M. (1993). Development during adolescence: The impact of stageenvironment fit on young adolescents' experiences in schools and in families. American Psychologist, 48(2), 90-101.

Education Week. (2011). Rural education. Retrieved from http://www.edweek.org/ew/issues/rural-education/.

Fagan, T. K. \& Hughes, J. (1985). Rural school psychology: Perspectives on lessons learned and future directions. School Psychology Review, 14(4), 444-451.

Gendron, B. P., Williams, K. R., \& Guerra, N. G. (2011). An analysis of bullying among students within schools: Estimating the effects of individual normative beliefs, self-esteem, and school climate. Journal of School Violence, 10, 150-164. doi:10.1080/15388220.2010.539166

Good, T. L. \& Weinstein, R. S. (1986). Schools make a difference: Evidence, criticisms, and new directions. American Psychologist, 41(10), 1090-1097. doi:10.1037/0003-066X.41.10.1090 
Goodenow, C. (1993). Classroom belonging among early adolescent students: Relationships to motivation and achievement. The Journal of Early Adolescence, 13(1), 21-43. doi:10.1177/0272431693013001002

Gottfredson, G. D., Gottfredson, D. C., Payne, A. A., \& Gottfredson, N.C. (2005). School climate predictors of school disorder: Results from a national study of delinquency prevention in schools. Journal of Research in Crime and Delinquency, 42, 412-444. doi:10.1177/0022427804271931

Gregory, A., Cornell, D., \& Fan, X. (2011). The relationship of school structure and support to suspension rates for black and white high school students. American Educational Research Journal, 48, 904-934. doi:10.3102/0002831211398531

Helge D. (1985). The school psychologist in the rural education context. School Psychology Review, 14(4), 402-420. Retrieved from http://jrre.psu.edu/articles 121-5.pdf.

Hertz, M. F. \& Donato, I. (2013). Bullying and suicide: a public health approach. Journal Adolescent Health, 53, S1-S3. doi:10.1016/j.jadohealth.2013.05.002

Hoge, D. R., Smit, E. K., \& Hanson, S. L. (1990). School experiences predicting changes in self-esteem of sixth- and seventh-grade students. Journal of Educational Psychology, 82(1), 117-127. doi:10.1037/0022-0663.82.1.117

Hopson, L. M. \& Lee, E. (2011) Mitigating the effect of family poverty on academic and behavioral outcomes: The role of school climate in middle and high school. Children and Youth Services Review, 33, 2221-2229. doi:10.1016/j.childyouth.2011.07.006

Hughes, J. N. \& Fagan, T. K. (1985). The challenges of rural school psychology. School Psychology Review, 14(4).

Illinois State Board of Education (2014). Illinois report card. Retrieved from https://illinoisreportcard.com.

John Hopkins University (2010). Prevalence of underage drinking. Retrieved from http://www.camy.org/factsheets/sheets/Prevalence_of_Underage_Drinking.html.

Johnston, L. D., O’Malley, P. M., Bachman, J. G., \& Schulenberg, J. E. (2012).

Monitoring the future: National survey results on drug use 1975-2012. Secondary School Students, 1. Retrieved from http://www.monitoringthefuture.org/pubs/monographs/mtf-vol1_2012.pdf. 
Kahn, J. H. (2011). Multilevel modeling and applications to research in counseling psychology. Journal of Counseling Psychology, 58(2), 257-271. doi: $10.1037 / \mathrm{a} 0022680$

Kärnä, A., Voeten, M., Poskiparta, E., \& Salmivalli, C. (2010). Vulnerable children in varying classroom contexts. Merrill-Palmer Quarterly, 56, 261-282. doi: $10.1353 / \mathrm{mpq} .0 .0052$

Kasen, S., Johnson, J., \& Cohen, P. (1990). The impact of school emotional climate on student psychopathology. Journal of Abnormal Child Psychology, 18, 165-177.

Kasen, S., Cohen, P., \& Brook, J. S. (1998). Adolescent school experiences and dropout, adolescent pregnancy, and young adult deviant behavior. Journal of Adolescent Research, 13, 49-72. doi:10.1177/0743554898131004

Kazdin, A. E., Kraemer, H. C., Kessler, R. C., Kupfer, D. J., \& Offord, D. R. (1997). Contributions of risk-factor research to developmental psychopathology. Clinical Psychology Review, 17, 375-406. doi:072-7358/97

Kessler, R. C., Berglund, P., Demler, O., Jin, R., Merikangas, K. R., \& Walters, E. E. (2005). Lifetime prevalence and age-of-onset distributions of DSM-IV disorders in the National Comorbidity Survey Replication. Archives of General Psychiatry, 62(6), 593-602. doi: 10.1001/archpsyc.62.6.593.

Kim, H. Y., Schwartz, K., Capella, E., \& Seidman, E. (2014). Navigating middle grades: Role of social contexts in middle grade school climate. American Journal of Community Psychology, 54, 28-45. doi:10.1007/s10464-014-9659-x

Kosciw, J. G., Greytak, E. A., Diaz, E. M. (2009). Who, what, where, when, and why: Demographic and ecological factors contributing to hostile school climate for lesbian, gay, bisexual, and transgender youth. Journal of Youth Adolescence, 38, 976-988. doi:10.1007/s10964-009-9412-1

Koth, C. W., Bradshaw, C. P., \& Leaf, P. J. (2008). A multilevel study of predictors of student perceptions of school climate: The effect of classroom-level factors. Journal of Educational Psychology, 100, 96-104. doi:10.1037/00220663.100.1.96

Kramer, J. J. \& Peters, G. J. (1985). What we know about rural school psychology: A brief review and analysis. School Psychology Review, 14(14), 452-456.

Kuperminc, G., Leadbeater, B. J., Emmons, C., \& Blatt, S. J. (1997). Perceived school climate and difficulties in the social adjustment of middle school students. Applied Developmental Science, 1(2), 76-88, doi:10.1207/s1532480xads0102_2 
Kuperminc, G. P., Leadbeater, B. J., \& Blatt, S. J. (2001). School social climate and individual differences in vulnerability to psychopathology. Journal of School Psychology, 39, 141- 159. doi:0022-4405/01

LaRusso, M. D., Romer, D., \& Selman, R. L. (2007). Teachers as builders of respectful school climates: Implications for adolescent drug use norms and depressive symptoms in high school. Journal of Youth Adolescence, 37, 386-398. doi:10.1007/s10964-007-9212-4

LaRusso M. \& Selman, R. (2011). Early adolescent health risk behaviors, conflict resolution strategies, and school climate. Journal of Applied Developmental Psychology, 32, 354-362. doi:10.1016/j.appdev.2011.05.003

Loukas, A. (2007). What is school climate? Leadership Compass, 5(1). Retrieved from http://www.naesp.org/resources/2/Leadership_Compass/2007/LC2007v5n1a4.pdf.

Lambert, D., Ziller, E. C., \& Lenardson, J. D. (2009). Rural children don't receive the mental health care they need. Retrieved from https://muskie.usm.maine.edu/Publications/rural/pb39/Rural-Children-MentalHealth-Services.pdf.

Masten, A. S. (2007). Resilience in developing systems: Progress and promise as the fourth wave rises. Development and Psychopathology, 19, 921-930. doi:10.1017/S0954579407000442

McGraw, K., Moore, S., Fuller, A., \& Bates, G. (2008). Family, peer, and school connectedness in final year secondary school students. Australian Psychologist, 43(1), 27-37. doi: $10.1080 / 00050060701668637$

McMahon, R. J. \& Frick, P. J. (2005). Evidence-based assessment of conduct problems in children and adolescents. Journal of Clinical Child and Adolescent Psychology, 34, 477-505. doi:10.1207/s15374424jccp3403_6

Midgley, C., Feldlaufer, H., \& Eccles, J. S. (1989). Change in teacher efficacy and student self-and task-related beliefs in mathematics during the transition to junior high school. Journal of Educational Psychology, 81(2), 247. doi: 0022-0663/89

Mitra, D. L. (2004). The significance of students: Can increasing "student voice" in schools lead to gains in youth development. Teachers College Record, 106(4). $651-688$

Nasir, N. S., Jones, A. McLaughlin, M. (2011). School connectedness for students in lowincome urban high schools. Teachers College Record, 113(8), 1755-1793. 
National Institute for Mental Health. (2015). Children's mental health awareness: depression in children and adolescent fact sheet. Retrieved from http://www.nimh.nih.gov/health/publications/depression-in-children-andadolescents/index.shtml.

National School Climate Center. (2013). School climate. Retrieved from http://www.schoolclimate.org/climate/.

National School Climate Center. (2009). National school climate standards: Benchmarks to promote effective teaching, learning, and comprehensive school improvement. Retrieved from http://www.schoolclimate.org/climate/documents/school-climatestandards-csee.pdf.

Nickerson A. B. \& Spears, W. H. (2007). Influences on authoritarian and educational/therapeutic approaches to school violence prevention. Journal of School Violence, 6(4), 3-31. doi:10.1300/j202v06n04_02

O’Brennan, L. M. \& Furlong, M. J. (2010). Relations between students' perceptions of school connectedness and peer victimization. Journal of School Violence, 9, 375391. doi:10.1080/15388220.2010.509009

Osher, D., Sprague, J., Weissberg, R. P., Axelrod, J., Keenan, S., Kendziora, K., \& Zins, Jo. E. (2008). A comprehensive approach to promoting social, emotional, and academic growth in contemporary schools. In Thomas, A. \& Grimes, J. (Eds.), Best practices in school psychology (pp. 1263-1278). Bethesda, MD: NASP Publications.

Pagano, M. E., Cassidy, L. J., Little, M., Murphy, J. M., \& Jellinek, M. S. (2000). Identifying psychosocial dysfunction in school-age children: the pediatric symptoms checklist as a self-report measure. Psychology in the Schools, 37(2), 91-106. doi:10.1002/(SICI)1520-6807(200003)37:2<91::AID- PITS1>3.0.CO;2-3

Pajares, F. \& Graham, L. (1999). Self-efficacy, motivation constructs, and mathematics performance of entering middle school students. Contemporary Educational Psychology, 24(2), pp. 124-139). doi: 0361-476X/99

Piscatelli, J. \& Lee, C. (2011). State policies on school climate and bully prevention efforts: challenges and opportunities for deepening state policy support for safe and civil schools. Retrieved from http://schoolclimate.org/climate/policy.php.

Raudenbush, S. W., \& Bryk, A. S. (2002). Hierarchical Linear Models: Applications and Data Analysis Methods ( $2^{\text {nd }}$ ed., Vol 1). Thousand Oaks, CA: Sage Publications. 
Reynolds, C. R. \& Kamphaus, R. W. (2004). BASC-2: Behavior assessment system for children, second edition. Circle Pines, MN: American Guidance Service.

Sadker, D. M. \& Zittleman, K. R. (2007). Teachers, schools, and society: A brief introduction to education. New York: McGraw-Hill.

Santrock, J. W. (2008). Adolescence, twelfth edition. New York: McGraw-Hill.

Schaps, E. (2002). Community in school: Central to character formation and more. Paper presented at the White House Conference, Washington D.C. Retrieved from https://www2.ed.gov/admins/lead/safety/character/schaps.pdf.

Shirley, E. L. M. \& Cornell, D. G. (2012). The contribution of student perceptions of school climate to understanding the disproportionate punishment of African American students in a middle school. School Psychology International, 33(2), 115-134. doi:10.1177/0143034311406815

Shochet, I. M., Dadds, M. R., Ham, D., \& Montague, R. (2006). School connectedness is an underemphasized parameter in adolescent mental health: results of a community prediction study. Journal of Clinical Child and Adolescent Psychology, 35, 170-179. doi:10.1207/s15374424jccp3502_1

Stewart, T. \& Suldo, S. (2011). Relationships between social support sources and early adolescents' mental health: the moderating effect of student achievement level. Psychology in the Schools, 48(10), 1016-1033. doi:10.1002/pits.20607

Strange, M., Johnson, J., Showalter, D., \& Klein, R. (2012). Why rural matters 2011-12: The condition of rural education in the 50 states. Retrieved from http://www.nwp.org/cs/public/download/nwp_file/15455/rural_school_communit y_trust_WRM2011-12.pdf?x-r=pcfile_d.

Suldo, S. M., McMahan, M. M., Chappel, A. M., \& Loker, T. (2012). Relationships between perceived school climate and adolescent mental health across genders. School Mental Health, 4, 69-80. doi:10.1007/s12310-012-9073-1

Thapa, A. (2013). School climate research. Retrieved from the National School Climate Center: http://www.schoolclimate.org/publications/documents/sc-briefresearch.pdf.

Thapa, A., Cohen, J., Guffey, S., \& Higgins-D’Alessandro, A. (2013). A review of school climate research. Review of Educational Research, 83(3), 357-385. doi:10.3102/0034654313483907 
Thomas, A. R. (1976). The organizational climate of schools. International Review of Education, 22(4), 441-463.

Roby, D. E. (2003). Research on school attendance and student achievement: a study of Ohio schools. Educational Research Quarterly, 28(1), 4-15.

U.S. Department of Education. (2010). Successful, safe, and healthy students. Retrieved from http://www2.ed.gov/policy/elsec/leg/blueprint/successful-safe-healthy.pdf.

Way, N., Reddy, R., \& Rhodes, J. (2007). Students' perceptions of school climate during the middle school years: associations with trajectories of psychological and behavioral adjustment. American Journal of Community Psychology, 40, 194-213. doi:10.1007/s10464-007-9143-y

Zaykowski, H. \& Gunter, W. (2011). Youth victimization: school climate or deviant lifestyles? Journal of Interpersonal Violence, 27, 431-452. doi:

$10.1177 / 0886260511421678$ 